\title{
Variability of mixed-phase clouds in the Arctic with a focus on the Svalbard region: a study based on spaceborne active remote sensing
}

\author{
G. Mioche ${ }^{1,2}$, O. Jourdan ${ }^{1,2}$, M. Ceccaldi ${ }^{3}$, and J. Delanoё $\ddot{~}^{3}$ \\ ${ }^{1}$ Université Clermont Auvergne, Université Blaise Pascal, OPGC, Laboratoire de Météorologie Physique, \\ BP 10448, 63000 Clermont-Ferrand, France \\ ${ }^{2}$ CNRS, UMR 6016, LaMP/OPGC, BP80026, 63177 Aubière, France \\ ${ }^{3}$ Laboratoire Atmosphère, Milieux et Observations Spatiales, UVSQ/CNRS/UPMC-IPSL, 78035, \\ Guyancourt, France
}

Correspondence to: O. Jourdan (o.jourdan@opgc.univ-bpclermont.fr)

Received: 16 July 2014 - Published in Atmos. Chem. Phys. Discuss.: 11 September 2014

Revised: 13 January 2015 - Accepted: 9 February 2015 - Published: 5 March 2015

\begin{abstract}
The Arctic region is known to be very sensitive to climate change. Clouds and in particular mixed-phase clouds (MPCs) remain one of the greatest sources of uncertainties in the modelling of the Arctic response to climate change due to an inaccurate representation of their variability and their quantification. In this study, we present a characterisation of the vertical, spatial and seasonal variability of Arctic clouds and MPCs over the entire Arctic region based on satellite active remote sensing observations. MPC properties in the region of the Svalbard archipelago $\left(78^{\circ} \mathrm{N}, 15^{\circ} \mathrm{E}\right)$ are also investigated. The occurrence frequency of clouds and MPCs are determined from CALIPSO/CLOUDSAT measurements processed with the DARDAR retrieval algorithm, which allow for a reliable cloud thermodynamic phase classification (warm liquid, supercooled liquid, ice, mixing of ice and supercooled liquid). Significant differences are observed between MPC properties over the entire Arctic region and over the Svalbard region. Results show that MPCs are encountered all year long, with a minimum occurrence of $30 \%$ in winter and $50 \%$ during the rest of the year on average over the entire Arctic. Over the Svalbard region, MPC occurrence is more constant with time with larger values (55\%) compared to the average observed in the Arctic. MPCs are especially located at low altitudes, below $3000 \mathrm{~m}$, where their frequency of occurrence reaches $90 \%$, particularly during winter, spring and autumn. Moreover, results highlight that MPCs are statistically more frequent above open sea than
\end{abstract}

land or sea ice. The temporal and spatial distribution of MPCs over the Svalbard region seems to be linked to the supply of moister air and warmer water from the North Atlantic Ocean, which contribute to the initiation of the liquid water phase. Over the whole Arctic, and particularly in western regions, the increase of MPC occurrence from spring to autumn could be connected to the sea ice melting. During this period, the open water transports some of the warm water from the North Atlantic Ocean to the rest of the Arctic region. This facilitates the vertical transfer of moisture and thus the persistence of the liquid phase. Particular attention is also paid to the measurement uncertainties and how they could affect our conclusions.

\section{Introduction}

It is now well established that the Arctic region is more sensitive to climate change than any other regions of the world (Sanderson et al., 2011; Serreze et al., 2009; Solomon et al., 2007). Solar elevation or surface albedo, for instance, are responsible for strong feedback mechanisms leading to the socalled Arctic amplification. Clouds are one of the main components driving the Arctic climate system as they play a key role in the radiation budget (Curry, 1995; Curry et al., 1996; Garrett et al., 2009). They interact with shortwave and longwave radiations, cooling or warming the surface and the at- 
mosphere depending on their macrophysical and microphysical properties. The low sun elevation in summer and the lack of solar radiation during the winter polar night are responsible for the predominant longwave radiative effect in the Arctic (Lubin and Vogelmann, 2006), tending to a regional net warming effect.

However, our sparse knowledge of cloud-radiation interactions and cloud properties at high latitudes remains one of the main source of uncertainties in predicting future climate by numerical simulations (Solomon et al., 2007; Stephens, 2005). In particular, the determination of the cloud thermodynamic phase is crucial for assessing the cloud radiative impact and hence, its influence on the radiation budget and climate feedbacks (Choi et al., 2014; Komurcu et al., 2014).

In addition, the Arctic is known for the frequent occurrence of mixed-phase clouds (hereafter referred to as MPCs) especially near the surface, wherein liquid droplets and ice crystals coexist (Curry et al., 2000; Korolev and Isaac, 2003; Shupe, 2011). In particular, these clouds exert a large influence on the surface radiation budget Shupe and Intrieri, 2004). However, the inter-annual spatial variability of Arctic MPC properties has been poorly quantified at a large scale. An assessment of the annual variability of MPCs was performed during the Surface Heat Budget of the Arctic Ocean experiment (SHEBA, Uttal et al., 2002), showing that MPC and liquid-containing clouds are prevalent over the Western Arctic Ocean. The SHEBA experiment highlighted that liquid-containing clouds (i.e. including supercooled and warm liquid clouds) over the Beaufort sea represent about $40 \%$ of the clouds during winter and reach more than $90 \%$ in summer (Intrieri et al., 2002). Additionally, Shupe et al. (2006) showed that nearly $60 \%$ of the clouds in the Arctic are MPCs.

Even though numerous observations, as well as numerical modelling focused on MPCs for several years (Verlinde et al., 2007; de Boer et al., 2009; Gayet et al., 2009; Jourdan et al., 2010; McFarquhar et al., 2011, among others), results still suffer from large uncertainties and important discrepancies are observed between observations and simulations (Chernokulsky and Mokhov, 2012; Klein et al., 2009; Morrison et al., 2009; Thomas et al., 2004).

This implies that our understanding of all steps of the MPC life cycle needs to be improved. Indeed, formation, development, persistence and dissipation of MPCs are governed by a combination of local and large-scale processes (Morrison et al., 2012). At the small scale, the Wegener-BergeronFindeisen (WBF) process is one of the main mechanisms responsible for ice crystals growth at the expense of supercooled water droplets (Bergeron, 1935; Findeisen, 1938; Wegener, 1911). Such a mechanism leads to a rapid glaciation of the MPCs. On the other hand, dynamical processes, such as turbulence or entrainment may facilitate the formation of new supercooled water droplets. For example, resupply of water vapour from the surface or from entrainment of moisture above the clouds may contribute to the continuous for- mation of liquid droplets within MPC. The coupling of such various processes is, thus, necessary to maintain the unstable equilibrium between liquid droplets and ice crystals within MPCs. This may explain the longevity of MPCs, which can last up to several days or weeks as has been frequently observed (Shupe, 2011; Verlinde et al., 2007; Morrison et al., 2012). Previous studies from Korolev et al. (2003), Korolev and Isaac, (2003) and Korolev (2007) also point out that the lifetime of MPCs could not be simply reduced to the WBF process, but also depends on numerous parameters such as local thermodynamical conditions or is linked to cloud dynamics. Local and long-range dynamic processes are also involved in aerosol, heat and moisture transport, which have a significant impact on Arctic MPC formation and properties (Cesana et al., 2012; Morrison et al., 2012; Shupe and Intrieri, 2004). It remains, therefore, difficult to fully understand the complexity of interactions between all these processes and to assert which of them play a key role in the MPC evolution (Harrington et al., 1999; Morrison et al., 2012).

The characterisation of the Arctic cloud mixed-phase state at both global and local scales is not yet accurately described, since the remote and extreme conditions encountered in this region of the world remain particularly challenging. For these reasons observations remain very sparse. Ice crystals and liquid droplets exhibit significantly different microphysical and optical properties (number, size, shape), leading to different interactions with radiation. The impact of mixed-phase clouds on the energy budget and climate is thus strongly dependent on the ice/liquid partitioning. Moreover, the determination of separate properties of ice crystals and liquid droplets within the same sample volume remains challenging due to instrument limitations in both remote sensing and in situ measurements. Moreover, the definition of the "mixed-phase" state depends strongly on the observation scale (Baumgardner et al., 2012).

Multi and single-layer clouds are the two main MPC types frequently observed in the Arctic. Multi-layer MPCs consist of several supercooled liquid layers embedded in ice clouds at different altitude levels. Ice crystals precipitate from upper layers, feeding underneath layers or evaporating during sedimentation, leading to very complex interactions between ice crystals and droplets (Hobbs and Rangno, 1998; Luo et al., 2008). On the other hand, the typical single-layer MPC structure is characterised by the presence of a single supercooled liquid layer at cloud top and ice crystals below, precipitating down to the surface (Curry et al., 1997; Shupe et al., 2005; Verlinde et al., 2007; Gayet et al., 2009). These particular clouds have been frequently observed in situ in the Arctic at a smaller scale for several years in previous airborne experiments, such as:

- in 1994, the Beaufort and Arctic Storms Experiment (BASE, Curry et al. (1997); 
- in 1998, the First International Satellite Cloud Climatology Project (ISCCP) Regional Experiment Arctic Clouds Experiment (FIRE-ACE, Curry et al., 2000);

- in 2004, the Mixed-Phase Arctic Cloud Experiment (MPACE, Verlinde et al., 2007);

- in 2004 and 2007, the Arctic Study of Tropospheric cloud, Aerosol and Radiation (ASTAR, Gayet et al., 2009; Jourdan et al., 2010);

- in 2008, the Polar Study using Aircraft, Remote Sensing Surface Measurements and Models of Climate, Chemistry, Aerosols and Transport (POLARCAT, Delanoë et al. (2013) and the Indirect and Semi-Direct Aerosol Campaign (ISDAC, McFarquhar et al., 2011);

- in 2010, the Solar Radiation and Phase Discrimination of Arctic Clouds experiment (SORPIC, Bierwirth et al., 2013);

- in 2012, the study on the Vertical Distribution of Ice in Arctic clouds (VERDI, Klingebiel et al., 2015);

- in 2014, the Radiation-Aerosol-Cloud Experiment in the Arctic Circle (RACEPAC).

However, in situ measurements are by essence localised in time and space. It is therefore of great importance to know in which regional framework such observations are performed. So, a description of Arctic MPCs at regional scale is of utmost importance.

Although taking cloud measurements still remains challenging in this region, important progresses have been made over several years. In particular, several ground-based observation sites are now well equipped for cloud observations, such as Barrow $\left(71^{\circ} \mathrm{N}\right)$, Eureka $\left(80^{\circ} \mathrm{N}\right)$, Summit $\left(72^{\circ} \mathrm{N}\right)$ or Ny-Ålesund $\left(78^{\circ} \mathrm{N}\right)$ observatories. However, the instruments of each ground observatory may differ significantly from one site to another. Indeed, climatologies based on different instruments can be biased by the sensitivity of the instruments and their capability to operate in extreme conditions. For instance, it is quite difficult to compare results derived from a lidar and from a cloud radar as they will not be sensitive to the same hydrometeors. During the past decade, the emergence of spaceborne observation platforms has provided a large amount of cloud-related data (Advanced Very High Resolution radiometer (AVHRR); International Satellite Cloud Climatology Project (ISCCP); Moderate Resolution Imaging Spectroradiometer (MODIS), A-Train). Unlike ground-based sites, they present the great advantage to involve a uniform measurement technique with a very large coverage.

Observations based on passive remote sensing measurements performed by instruments such as AVHRR, ISCCP, MODIS (Frey et al., 2008; Key and Barry, 1989; Rossow and Garder, 1993) have well-known limitations in the Arctic region. Previous studies, based on comparisons with groundbased observations or spaceborne active remote sensing measurements, highlighted that passive remote sensing observations might drive to an underestimation of the cloud fraction by up to $35 \%$ Schweiger and Key, 1992), in particular at lowlevel altitudes (Chan and Comiso, 2013). These limitations are mostly due to the low contrast between clouds and the underlying surface.

Spaceborne active remote sensing is a recent alternative measurement technique that aims to reduce these limitations. This is the case for the new generation of spaceborne instrumentation onboard CALIPSO (Winker et al., 2003) and CLOUDSAT (Stephens et al., 2002) satellites. Since 2006, they perform lidar $(532 \mathrm{~nm}$ and $1064 \mathrm{~nm})$ and $\operatorname{radar}(94 \mathrm{GHz})$ measurements, and provide an unprecedented data set of the vertical structure of clouds, continuously in time and space (up to latitude $82^{\circ} \mathrm{N}$ ), even if these instruments have serious limitations regarding low clouds and multi-layered clouds, as it will be discussed below.

The aim of this study is to characterise the vertical, spatial and seasonal variability of Arctic MPCs at a regional scale from space remote sensing. A focus on MPC properties in the area around the Svalbard archipelago $\left(78^{\circ} \mathrm{N}, 15^{\circ} \mathrm{E}\right)$, which benefits from distinctive meteorological conditions due to the proximity of the North Atlantic Ocean compared to the rest of the Arctic, will also be performed. This will enable us to evaluate to which extent MPCs in this region are representative of their counterparts over the entire Arctic. In addition, this work will give an insight into the representativity of the numerous airborne cloud measurements made in this region for several years (ASTAR, POLARCAT, SORPIC among others).

This work is based on the lidar-radar spaceborne measurements synergy of CALIPSO/CLOUDSAT observations. Cloud thermodynamic phase and distribution are determined from DARDAR retrieval products (Delanoë and Hogan, 2008, 2010, and recently Ceccaldi et al., 2013). Then properties over the Svalbard region are investigated and compared to those at the regional scale. Section 2 describes the DARDAR retrieval algorithm and presents the data set used and the method applied to detect MPC and determine cloud occurrences. In this section, uncertainties and limitations of DARDAR retrievals are analysed. In Sect. 3, total cloud occurrence determined from DARDAR products is first compared to previous works in order to validate the methodology. Then Sect. 4 focuses on mixed-phase clouds variability at regional scale and over the region of Svalbard. In Sect. 5, regional and local MPC properties are compared and differences observed between the whole Arctic and the Svalbard region are discussed. 
Table 1. DARDAR classes used in V1 version.

\begin{tabular}{cl}
\hline Class number & Definition \\
\hline-9 & Unknown \\
-1 & Surface and subsurface \\
0 & Clear sky \\
1 & Ice only \\
2 & Ice + supercooled water \\
3 & Warm liquid \\
4 & Supercooled water only \\
5 & Rain or drizzle \\
6 & Aerosols \\
7 & Possibly insects \\
8 & Stratospheric features \\
\hline
\end{tabular}

\section{Data and method}

Cloud thermodynamic phase distributions over the Arctic region are studied using CALIPSO and CLOUDSAT measurements. Active remote sensing observations are expected to provide a detailed characterisation of the cloud vertical structure in the Arctic. Indeed, compared to passive instruments, active remote sensing techniques are less disturbed by the important Arctic ice cover throughout the year or the lack of sunlight during the polar night (Chan and Comiso, 2013; Liu et al., 2010; Wang and Key, 2005).

\subsection{DARDAR retrieval algorithm}

The present study is based on the operational DARDAR (for raDAR/liDAR) retrieval products. The DARDAR algorithm (Delanoë and Hogan, 2008, 2010) exploits the synergy of CALIPSO and CLOUDSAT observations to retrieve vertical profiles of cloud thermodynamic phase (DARDAR-MASK product) and ice cloud properties (DARDAR-CLOUD product). These products are now widely used for cloud studies (Delanoë et al., 2013; Huang et al., 2012; Jouan et al., 2012, 2014). DARDAR-MASK algorithm uses Level 1B CALIPSO $532 \mathrm{~nm}$ lidar backscatter coefficient profiles, "2BGEOPROF" CLOUDSAT $94 \mathrm{GHz}$ radar reflectivity, as well as thermodynamic variables (pressure, temperature, humidity) from "ECMWF-AUX" products. It presents the great advantage of being able to merge all of these data on the same resolution grid and to allow the cloud phase discrimination. Pixel size along the track is $60 \mathrm{~m}$ vertically and $1.7 \mathrm{~km}$ horizontally. The combination of both lidar and radar cloud masks is used to classify the cloud hydrometeors phase. The main steps of the algorithm for cloud thermodynamic phase retrieval are summarised in Fig. 1 and all DARDAR retrieval classes are summarised in Table 1. This includes surface and clear sky detection (class -1 and 0 respectively), cloudy pixels with ice only (class 1), mixing of ice and supercooled water (class 2), warm liquid cloud (class 3), supercooled liquid (class 4), rain (class 5) as well as stratospheric features

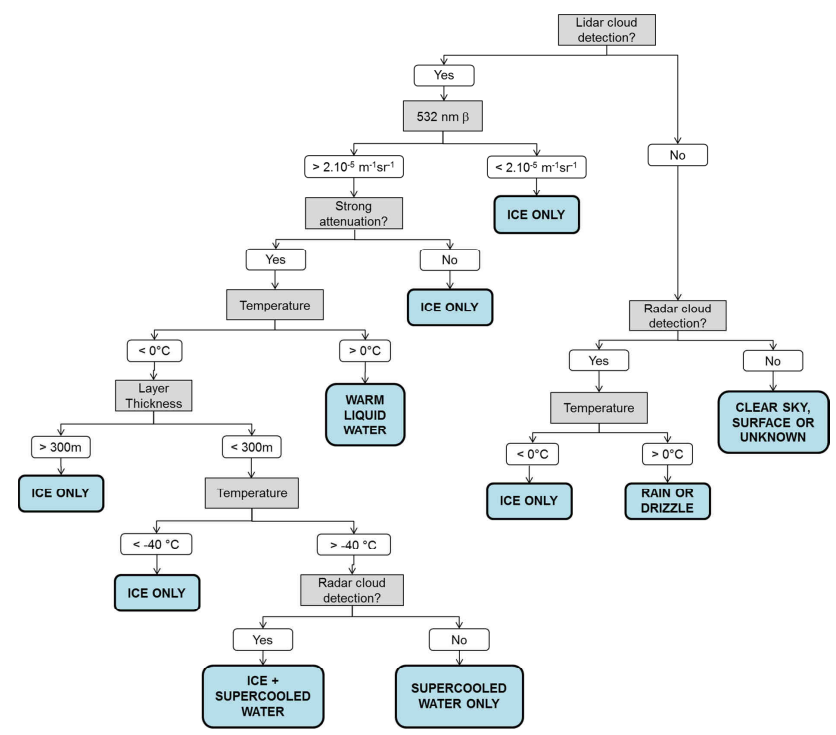

Figure 1. Representation of the DARDAR algorithm retrieval steps for cloud thermodynamic phase.

(class 8), and aerosols and insects detection (class 6 and 7 respectively). In particular, a cloud layer is classified as supercooled water if its lidar backscatter signal, $\beta$, is higher than $2.10^{-5} \mathrm{~m}^{-1} \mathrm{sr}^{-1}$ and if it strongly (at least 10 times) and rapidly (in the next $480 \mathrm{~m}$ ) attenuates the lidar signal. Note that the lidar is very sensitive to small drops in high concentration and therefore the backscattered signal, in presence of liquid drops, is very high and a strong attenuation is expected below the backscattering peak. Moreover, to be classified as supercooled water, a cloud layer needs to be located in the temperature range from 0 to $-40^{\circ} \mathrm{C}$ (temperature of homogenous nucleation) and to have a penetration depth (detected by the lidar) thinner than $300 \mathrm{~m}$. When supercooled water is detected, confident detection of cloud features by radar (i.e. when CLOUDSAT cloud mask values are greater than 30, according to Mace (2007)) determines if ice is present or not in the same sample volume. All cloud features with a temperature less than $-40^{\circ} \mathrm{C}$ are considered as ice. This retrieval technique only works when the lidar is operational.

A complete description of DARDAR algorithm is presented in Delanoë and Hogan $(2008,2010)$ and in Ceccaldi et al. (2013). Version 1 of DARDAR-MASK (v. 1.1.4), distributed by the French data centre ICARE, is used in this study and provides a categorisation of pixels according to the classes summarised in Table 1.

\subsection{Data set and methodology}

In this study, mixed-phase clouds are defined based on DARDAR classification. All DARDAR pixels satisfying one of the following two conditions are assumed to belong to MPCs: 
- they are classified as a mixing of ice and supercooled water (class 2, see Table 1);

- they are classified as supercooled only (class 4, see Table 1) associated with the presence of ice or ice and supercooled water mixing in the three vertical adjacent pixels.

Note that "isolated" supercooled water pixels are not classified as mixed-phase clouds.

The annual and seasonal variability of the total cloud fraction and MPC is investigated using CALIPSO/CLOUDSAT measurements performed continuously from 2007 to 2010 . In this study the Arctic region is defined by all latitudes between $60^{\circ} \mathrm{N}$ (Liu et al., 2012) and $82^{\circ} \mathrm{N}$ (upper limit of CALIPSO/CLOUDSAT measurements) and the Svalbard region is defined as the area between $0^{\circ}$ and $30^{\circ} \mathrm{E}$ of longitude and $75^{\circ}$ and $80^{\circ} \mathrm{N}$ of latitude.

The spatial frequency of occurrence and vertical distributions are determined for both total cloud and MPC. The spatial distribution of clouds is studied for altitudes spanning from $500 \mathrm{~m}$ up to $12 \mathrm{~km}$ (according to the study of Liu et al., 2012) as well as for low-level altitudes ranging between $500 \mathrm{~m}$ and $3 \mathrm{~km}$ (according to Zygmuntowska et al., 2012). A minimum altitude of $500 \mathrm{~m}$ is chosen to avoid surface contamination in the CLOUDSAT data (Marchand et al., 2008) and also to avoid false water detection (due to the lidar high backscattered signal from the ground) in the DARDAR algorithm. These instrument shortcomings will be discussed further in Sect. 2.3. The seasonal occurrence is calculated for March-April-May (MAM for spring), June-July-August (JJA for summer), September-October-November (SON for autumn) and December-January-February (DJF for winter). The horizontal spatial resolution of cloud occurrence is $5^{\circ}$ in longitude and $2^{\circ}$ in latitude and the vertical resolution is $60 \mathrm{~m}$ for the profiles.

For each season (or month), cloud and MPC spatial occurrences (hereafter $F_{\mathrm{CLOUD}}$ and $F_{\mathrm{MPC}}$ ) in each box of $2^{\circ}$ latitude ( $\Delta$ lat) by $5^{\circ}$ longitude ( $\Delta$ long), are computed according to Eq. (1) and (2), where $(i, j)$ are the latitudes and longitudes of the CALIPSO/CLOUDSAT granules falling into the box ( $\Delta$ lat width by $\Delta$ long length). $\mathrm{N}_{\text {footprints }}$ is the total number of footprints in the box.

$$
\begin{aligned}
& F_{\text {CLOUd }}(\Delta \text { lat }, \Delta \text { long })=\frac{\sum_{i, j} N_{\text {CLOUD }}(i, j)}{N_{\text {footprints }}} \\
& F_{\text {MPC }}(\Delta \text { lat }, \Delta \text { long })=\frac{\sum_{i, j} N_{\text {MPC }}(i, j)}{\sum_{i, j} N_{\text {CLOUD }}(i, j)}
\end{aligned}
$$

$\mathrm{N}_{\text {CLOUD }}\left(\mathrm{i}, \mathrm{j}\right.$ ) (and $\mathrm{N}_{\text {MPC }}(\mathrm{i}, \mathrm{j})$ ) is the occurrence of all clouds (and MPCs) in the atmospheric column at latitude $i$ and longitude $j$, and is defined according to Eq. (3), where $z_{\min }$ and $z_{\max }$ are the altitude boundaries for occurrence calculation. $z_{\min }=500 \mathrm{~m}$ and $z_{\max }=12 \mathrm{~km}$ or $3 \mathrm{~km}$ depending on the altitude range taken into account (all-level or low-level domain respectively). $\mathrm{n}_{\text {CLOUD }}(\mathrm{i}, \mathrm{j}, \mathrm{z})$ (and $\mathrm{n}_{\mathrm{MPC}}(\mathrm{i}, \mathrm{j}, \mathrm{z})$ ) refers to the detection of clouds (and MPCs) at altitude $z$ and coordinates $(i, j)$. It is equal to 1 if cloud (or MPC) is present, and 0 if not. The presence of cloud (and MPC) is detected in each atmospheric column if at least three consecutive pixels (i.e. minimum thickness of $180 \mathrm{~m}$ ) are classified as cloud (MPC) by DARDAR.

$$
\begin{aligned}
N_{\text {CLOUD or } \operatorname{MPC}}(i, j) & =1 \quad \text { if } \sum_{z_{\min }}^{z_{\max }} n_{\mathrm{CLOUD}} \text { or } \operatorname{MPC}(i, j, z) \geq 3 \\
& =0 \quad \text { if } \sum_{z_{\min }}^{z_{\max }} n_{\mathrm{CLOUD}} \operatorname{MPC}(i, j, z)<3
\end{aligned}
$$

The vertical distribution of MPC occurrence (hereafter $\left.F_{\text {MPC }}(z)\right)$ is computed at each altitude level $z$, according to Eq. (4) where $i$ and $j$ are the latitudes and longitudes of the CALIPSO/CLOUDSAT granules falling into the considered domain, i.e. the Svalbard region $\left(75-80^{\circ} \mathrm{N}, 0-30^{\circ} \mathrm{E}\right)$ or the whole Arctic region (area between $60^{\circ} \mathrm{N}$ and $82^{\circ} \mathrm{N}$ ).

$F_{\mathrm{MPC}}(z)=\frac{\sum_{i, j} N_{\mathrm{MPC}}(i, j, z)}{\sum_{i, j} N_{\mathrm{CLOUD}}(i, j, z)}$

From Eqs. (1), (2), (3) and (4) on can note that $F_{\text {CLOUD }}$ refers to time and $F_{\mathrm{MPC}}$ and $F_{\mathrm{MPC}}(z)$ refer to time where cloud occurs.

\subsection{Uncertainties and limitations}

Before deriving a climatology of the MPC occurrence, we first have to keep in mind that our analysis of CALIPSO and CLOUDSAT observations and therefore DARDAR retrieval products suffer from uncertainties due to both measurement technique and the retrieval method. In the following we will discuss these limitations and their potential impact on the results presented in this study.

\subsubsection{Limitations of observations near the surface}

Space remote sensing has inherent and well-known shortcomings near the ground. For example, if the radar clutter is not properly removed, CLOUDSAT radar ground echoes lead to an overestimation of low-level cloud amount (Marchand et al., 2008). On the other hand, the probability of total or partial attenuation of lidar laser beam by upper cloud layer increases when approaching ground level and could induce an underestimation of the low-level cloud amount assessed by the lidar. The difficulty for the DARDAR algorithm to distinguish ground lidar attenuated backscattering signal from an overlaying liquid layer is another shortcoming in the retrieval method, which can lead to a cloud misclassification. 
The final impact (overestimation or underestimation) of these different issues on low-level cloud occurrence remains uncertain.

\section{Ground contamination on CLOUDSAT data}

As described in Sect. 2.2., a minimum altitude threshold of $500 \mathrm{~m}$ is chosen to compute cloud occurrence. However, ground contamination could also affect CLOUDSAT cloud detection measurements above an altitude of $500 \mathrm{~m}$.

We recall that the DARDAR MASK algorithm is based on the CLOUDSAT cloud mask (and also the CALIPSO lidar mask) to classify pixels as clouds (Delanoë and Hogan, 2010). Regarding CLOUDSAT measurements, a pixel is considered as cloud if its radar mask reports a value of 30 or greater (indicating a high confidence in the cloud detection, according to Mace, 2007). Values smaller than this threshold are considered inaccurate and possibly contaminated by ground echoes. Therefore, DARDAR MASK algorithm excludes data contaminated by ground. This implies that the data set is reduced between $500 \mathrm{~m}$ and $1000 \mathrm{~m}$. The fraction of reliable data (clear sky or atmospheric features) has been determined and represents about $40 \%$ of the total data in this altitude range. The remaining $60 \%$ correspond to data assigned either to ground contamination on radar data $(70 \%)$ or to lidar total attenuation (30\%). This result gives an insight on how ground contamination affects the observations and reduces the data set in the $500 \mathrm{~m}-1 \mathrm{~km}$ altitude range.

Moreover, in previous studies, Kay and Gettelman (2009) used a detection altitude limit of $720 \mathrm{~m}$ to prevent false detection. On the other hand, Huang et al. (2012) showed that DARDAR data between $700 \mathrm{~m}$ and $1000 \mathrm{~m}$ were reliable for cloud occurrence determination. In the present study, a short sensitivity test is made by computing cloud occurrences with a threshold of $1000 \mathrm{~m}$ in order to check differences with the occurrences obtained with a $500 \mathrm{~m}$ altitude threshold. As expected, the use of a $1000 \mathrm{~m}$ threshold leads to a decrease of the cloud occurrences compared to a $500 \mathrm{~m}$ threshold. Differences lie between $4 \%$ and $18 \%$ depending on the cloud type and the altitude domain considered. These results are consistent with similar tests made on CALIPSO/CLOUDSAT standard NASA products by Zygmuntowska et al. (2012), showing that $F_{\text {CLOUD }}$ derived with a $1000 \mathrm{~m}$ minimum altitude threshold is smaller than the $F_{\text {CLOUD }}$ derived with a $500 \mathrm{~m}$ minimum altitude threshold by up to $26 \%$.

\section{Comparisons with ground-based observations}

The unique way to accurately assess and quantify the limitations of DARDAR products in the low-level altitude domain is to compare them with collocated ground-based measurements. Such a work has been recently done by Blanchard et al. (2014). They directly compared ground-based observations at the Eureka Arctic station, located in the Canadian archipelago $\left(80.2^{\circ} \mathrm{N}, 86.2^{\circ} \mathrm{W}\right.$, Nunavut, Canada), with col-
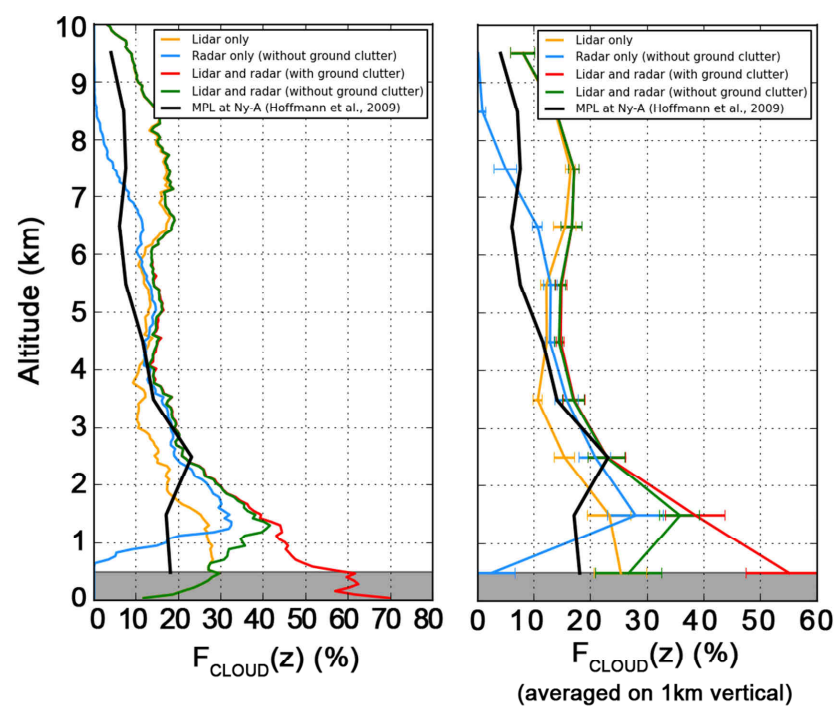

Figure 2. Vertical profiles of cloud occurrences over the NyÅlesund station during March and April 2007. The black line refers to ground-based lidar observations at $1 \mathrm{~km}$ vertical resolution (Hoffmann et al., 2009) and the coloured lines refer to a DARDAR product, according to different configurations and settings. DARDAR retrievals have a vertical resolution of $60 \mathrm{~m}$ on the left panel and $1 \mathrm{~km}$ on the right panel.

located A-Train observations and DARDAR products (V1 version). They performed a detailed study on cloud fraction and vertical distribution over the Eureka station, identifying and quantifying uncertainties and limitations of A-Train observations and DARDAR products. The largest differences occur below $2 \mathrm{~km}$ of altitude. The cloud fraction derived from spaceborne observations is lower than the one obtained from ground-based observations by $10 \%$ in the $500-1000 \mathrm{~m}$ altitude domain and by up to $25 \%$ at the $0-500 \mathrm{~m}$ altitude domain (see Fig. 5 from Blanchard et al., 2014). These differences are mainly attributed to undetected low-level clouds due to sensitivity loss of CALIOP lidar and surface proximity for CLOUDSAT radar, but also to the distance between satellites tracks and the ground station. Moreover, near the surface, ground-based measurements may be affected by local effects and cloud fraction may be overestimated by the presence of ice crystals or diamond dust close to the ground that are classified as clouds, as confirmed by in Shupe (2011) and Bourdages et al. (2009).

To complement the study of Blanchard et al. (2014) a short comparison is made between the occurrence of lowlevel clouds using the DARDAR product and the one derived from ground-based locations available in previous studies.

Figure 2 shows the comparison of the vertical profile of cloud occurrence from the DARDAR product (with various configurations and different settings, cf. legend of the figure) with that from Ny-Ålesund ground-based observations (Micro Pulse Lidar (MPL) measurements during March and 


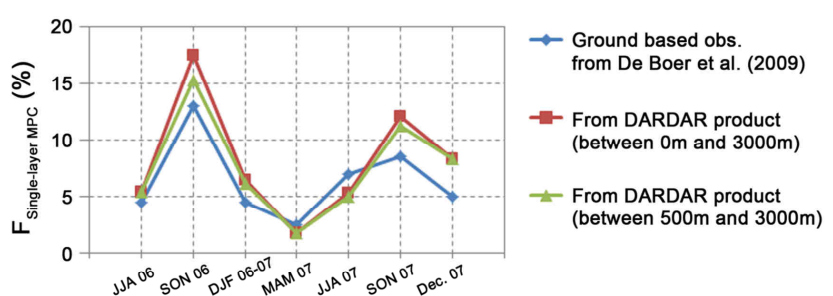

Figure 3. Seasonal occurrence of MPCs over the Eureka station from June 2006 to December 2007 from ground-based observations (blue line from De Boer et al., 2009) and from DARDAR product (green and red lines).

April 2007, see Hoffmann et al., 2009). Figure 2a displays DARDAR profiles at the original vertical resolution $(60 \mathrm{~m})$. In Fig. $2 b$ the DARDAR profiles are shown with $1 \mathrm{~km}$ vertical resolution, to be consistent with the measurements performed by Hoffmann et al. (2009). Above approximately $5 \mathrm{~km}$, DARDAR detects more cloud than the ground-based lidar. This is due to the attenuation of the ground-based lidar signal at high altitude levels. A proportion of high clouds, probably the optically thin ones, are also missed when considering radar measurements alone. These results are in agreement with those presented in Blanchard et al. (2014). Between 2 and $5 \mathrm{~km}$, space and ground-based observations agree quite well, as also shown in Blanchard et al. (2014). Below $2 \mathrm{~km}$, cloud occurrences from space observations are larger than from ground based by about $20 \%$ between $1 \mathrm{~km}$ and $2 \mathrm{~km}$, and by about $10 \%$ below $1 \mathrm{~km}$. One can also note that if ground clutter is not removed (red curve), cloud fraction may be greatly overestimated by up to $40 \%$.

Figure 3 displays ground-based observations of the singlelayer MPC seasonal occurrence over the Eureka station (from de Boer et al. (2009), blue line) as well as the one derived from DARDAR products (red and green lines). The results show that DARDAR and ground-based observations are in good agreement, in particular regarding the annual variability. The maximum discrepancies (5\%) occur in autumn even though no systematic bias can be identified. One can also note that the choice of a $500 \mathrm{~m}$ or $0 \mathrm{~m}$ minimum altitude threshold on DARDAR data does not significantly impact the cloud occurrence.

These results show that the variability of $F_{\mathrm{CLOUD}}$ or $F_{\mathrm{MPC}}$ determined from space observations agree well with groundbased observations. However, and in contrast to the results of Blanchard et al. (2014), our results do not highlight a systematic bias in the low-level cloud amount retrieved from space observations. It may be due to the small data set used for the comparisons (two months and several seasons), to the accuracy of the colocalisation in space or also due to the differences in the cloud and MPC occurrence determination method. It is obvious that a more detailed study based on comparisons of space and ground-based observations aiming to quantify the uncertainties in the low-level cloud amount is

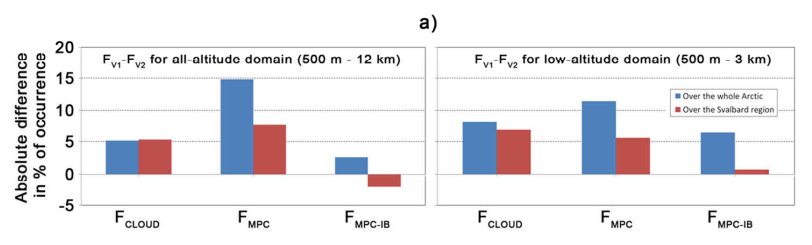

b)
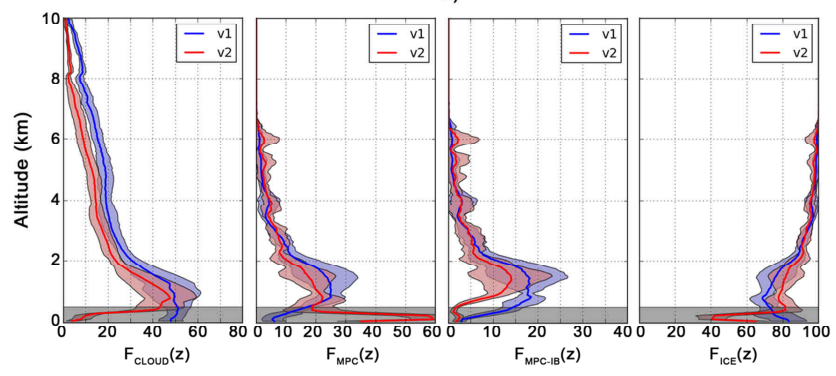

Figure 4. (a) Absolute differences in $\%$ of occurrence between occurrences computed from V1 and V2 DARDAR products for total cloud, MPC and MPC-IB and (b) mean vertical profiles of cloud, MPC, MPC-IB and ice cloud occurrences computed from V1 (blue lines) and V2 (red lines) DARDAR products for April 2007 over the Svalbard region. The filled areas represent the standard deviation.

needed and would be useful, but is beyond the scope of the present study.

The uncertainties of DARDAR products in the low-level altitude domain remain thus difficult to accurately assess, but some conclusions can be drawn regarding these results. First, the DARDAR product is reliable above $2 \mathrm{~km}$. Secondly, below $2 \mathrm{~km}$, uncertainties in cloud or MPC occurrence is up to $20 \%$ between $500 \mathrm{~m}$ and $2 \mathrm{~km}$, and up to $25 \%$ below $500 \mathrm{~m}$ when considering ground-based observations as a reference. This information will be considered in the discussion regarding cloud and MPC occurrences results below.

\subsubsection{Multiple layer clouds}

One more ambiguity concerning MPCs is the ability of remote sensing to detect several liquid layers. Indeed, the lidar suffers from a strong attenuation when liquid is present and therefore it is quite difficult to detect more than one supercooled liquid layer. Therefore, the detection of multi-layer MPCs from remote sensing observations may be biased, inducing an inaccurate classification of multi-layer MPCs in single-layer MPCs, and thus a possible overestimation of the ratio of single-layer MPCs to multi-layer ones. Note that so far none of the remote sensing techniques (ground or satellite) can address this. The only solution remains to fly an aircraft between two layers.

\subsubsection{DARDAR algorithm and assumptions}

An additional possible source of uncertainty concerns the DARDAR retrieval algorithm. DARDAR detects supercooled liquid (and warm liquid) layers from a strong lidar 
backscatter signal (see Fig. 1). But some additional pixels with a strong backscatter signal located above and below the liquid layer can also be misclassified as liquid. So, these additional supercooled pixels may lead to an overestimation of supercooled liquid water occurrence and supercooled liquid layers thickness. The present study uses version 1 of the DARDAR products, but a new algorithm (Ceccaldi et al., 2013) is expected to remove these additional pixels, which may be currently included in version 1 of DARDAR MASK. The detailed study by Ceccaldi et al. (2013) showed that ice fraction will increase by a factor of about $15 \%$ in the future version 2, associated to a decrease of the supercooled water fraction (up to $25 \%$ ), as compared to version 1. Therefore, version 1 may overestimate supercooled liquid layers thickness, and thus also the occurrence of mixed-phase clouds. However, the DARDAR V2 product is currently not available for the entire CALIPSO/CLOUDSAT data set, and the results from Ceccaldi et al. (2013) are based on one case study and 3 months of data only. So, in order to quantify how these differences can affect the results of the present study, comparisons are performed between the two product versions over 1 month of data (April 2007). Figure 4a shows differences between the two versions in terms of $F_{\text {CLOUD, }}$, $F_{\mathrm{MPC}}$ and $F_{\mathrm{MPC}-\mathrm{IB}}$ for the low-level and the all-level altitude domains. Differences lie between 3 and $15 \%$ for the whole Arctic, and between -2 and $8 \%$ on the Svalbard region. Figure $4 \mathrm{~b}$ presents the mean vertical profiles extracted from both data versions. The trends are similar but V2 present smaller values for clouds and MPC by about $5 \%$ whereas the ice phase is larger by around $5-10 \%$ in V2.

At last, as shown in Fig. 1, supercooled and mixed-phase pixels detection from the DARDAR algorithm is dependent on the a priori threshold considered for variables such as temperature or layer thickness. In particular, temperature is determined based on ECMWF reanalysis, and its accuracy may be a source of error in supercooled liquid retrieval algorithm. However, the ECMWF temperature uncertainty is estimated to $0.6 \mathrm{~K}$ (Benedetti, 2005), which is considered to be acceptable by Delanoë and Hogan (2010).

The Arctic region is considered northward $60^{\circ} \mathrm{N}$ in this study, as done in several previous studies (Cesana et al., 2012; Chernokulsky and Mokhov, 2012; Liu et al., 2012 among others). However, no real definition of the Arctic region is truly established, and some authors use a different limit, such as $65^{\circ} \mathrm{N}$ (Kay and Gettelman, 2009; Nygård et al., 2014), $68^{\circ} \mathrm{N}$ (Zygmuntowska et al., 2012) or $70^{\circ} \mathrm{N}$ (de Boer et al., 2012). These latitude boundaries were tested (not shown here) and the differences observed on clouds and MPCs occurrence are not significant since they vary only by a few percent (by less than $5 \%$ between 60 and $70^{\circ} \mathrm{N}$ limits).
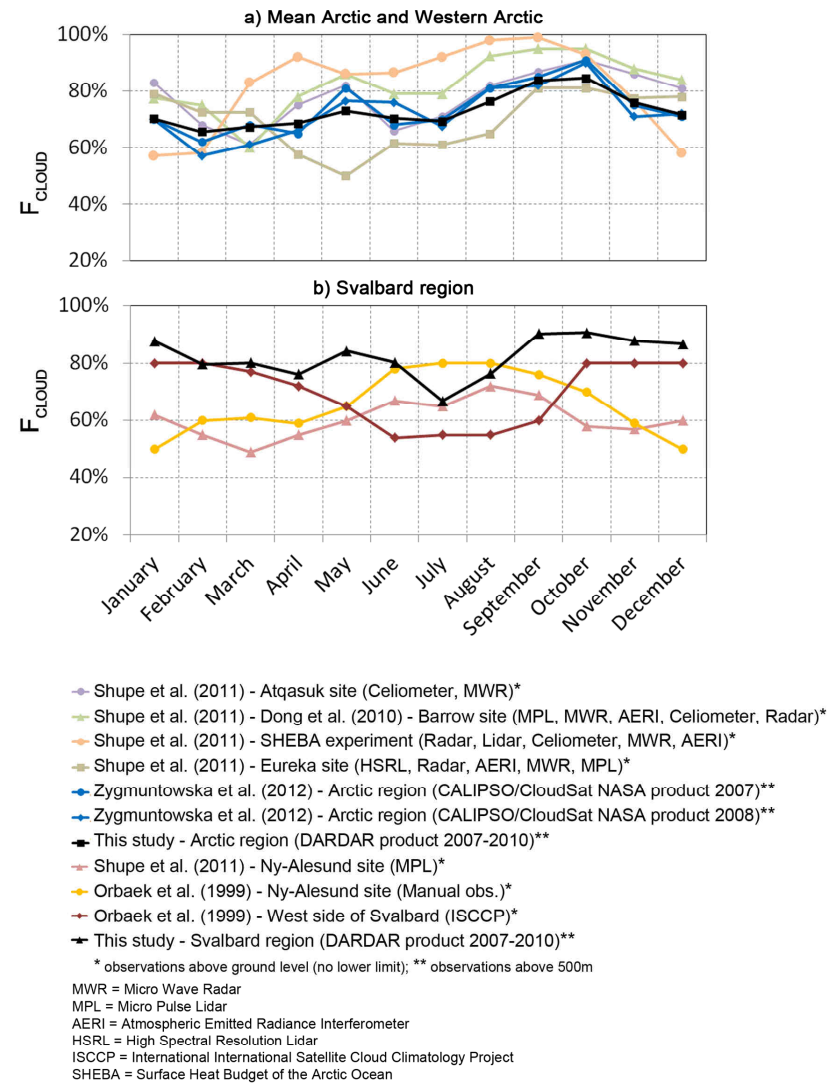

Figure 5. Monthly total cloud occurrence in the Arctic from ground and spaceborne remote sensing observations: (a) over the entire Arctic region and Western Arctic ground-based sites; (b) over the Svalbard region.

\section{Total cloud occurrence ( $\left.\boldsymbol{F}_{\text {CLOUD }}\right)$}

In this section, the total cloud occurrence ( $\left.F_{\text {CLOUD }}\right)$ derived from the DARDAR product is first compared to $F_{\text {CLOUD }}$ derived from the main ground based observations in the Arctic region available from previous studies.

Figure 5a shows the monthly total cloud occurrence $F_{\text {CLOUD }}$ over the Arctic region derived from DARDAR along with an overview of the main previous studies (namely Atqasuk, Barrow, Eureka, the Surface Heat Budget of the Arctic Ocean experiment (SHEBA), summarised in Orbaek et al. 1999; Dong et al., 2010; and Shupe et al., 2011 works), as well as the standard NASA CALIPSO/CLOUDSAT products for 2007 and 2008 (Zygmuntowska et al., 2012). Figure $5 \mathrm{~b}$ focuses on the Svalbard region and reports the monthly $F_{\text {CLOUD }}$ determined from DARDAR products, along with visual and MPL (Micro Pulse Lidar) ground-based observations in Ny-Ålesund and ISCCP measurements (Orbaek et al., 1999; Shupe et al., 2011).

Ground-based observations are expected to capture more accurately low-level clouds below $500 \mathrm{~m}$ Blanchard et al. (2014) and discussion in Sect. 2.3). This could explain the 
a)

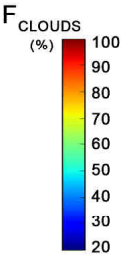

b)

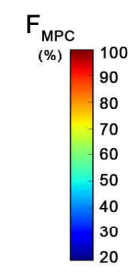

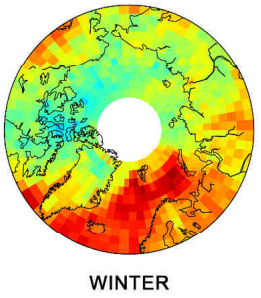

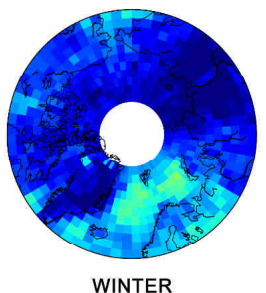

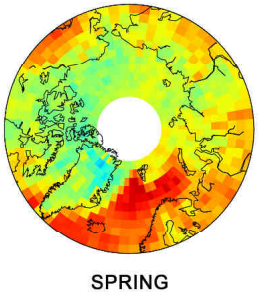

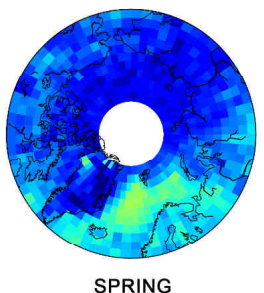

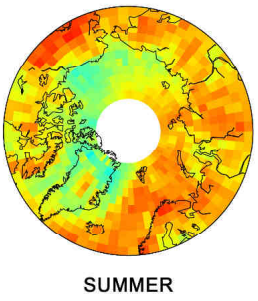
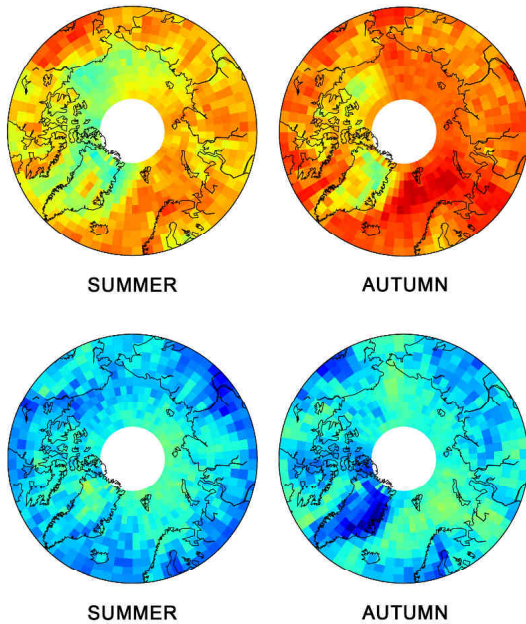

Figure 6. Stereographic projections of the seasonal occurrence of: (a) all clouds (referring to time) and (b) MPCs (referring to clouds). Occurrences are computed taking into account the 500 to $12000 \mathrm{~m}$ altitude range.

differences between space borne and ground-based measurements observed in Fig. 5a. However, the variability within the ground-based measurements still remains significant due to the discrepancies of the measurement techniques or the localisation of the observatories. Furthermore, comparing the annual or seasonal variability over Western Arctic regions (Fig. 5a) and over the Svalbard region (Fig. 5b), no noticeable trend is observed: in Fig. 5b, Ny-Ålesund ground visual and MPL observations show a maximum occurrence in summer and early autumn $(\sim 70-80 \%)$, while ISCCP observations display an opposite trend over the ocean on the west side of Svalbard. In the Western Arctic (SHEBA experiment and Eureka, Barrow and Atqasuk sites on Fig. 5a), cloud variability is significantly different as the majority of cloud occurrences are observed in spring and mostly in autumn, with values ranging from $80 \%$ to nearly $100 \%$.

The standard NASA retrieval products from CALIPSO/CLOUDSAT in 2007 and 2008 (2B-GEOPROFLIDAR products, Zygmuntowska et al., 2012) as well as the DARDAR products are also reported in Fig. 5a. Both products show an annual variability with two maxima in spring and autumn. As expected, NASA and DARDAR products are consistent, justifying the methodology based on DARDAR products proposed for this study. The small differences observed between the two products could result from the data processing methodology (differences linked to the geographical domain of the studied area and the surface type taken into account as well as the difference in the vertical resolution between NASA and DARDAR products). Figure $5 \mathrm{~b}$ shows that the annual variability of $F_{\text {CLOUD }}$ derived from active and passive space remote sensing observations (A-Train and ISCCP) are not in accordance with Ny-Ålesund ground-based measurements. Indeed, ground-based observations show a maximum of cloud occurrence during summer (between 60 and $80 \%$ ), while spaceborne observations show a minimum in that season.

Finally, Figs. 5a and b highlight that, except during summer, the Svalbard region exhibits a year-round total cloud occurrence exceeding the mean Arctic occurrence by at least $5 \%$. This is especially true in winter and spring, where the cloud occurrence over Svalbard is larger than the Arctic average by about $20 \%$.

\section{Mixed-phase clouds and single-layer mixed-phase clouds occurrence}

The arctic stereographic projections of the mean seasonal occurrences of clouds ( $\left.F_{\mathrm{CLOUD}}\right)$ and MPC in particular $\left(F_{\mathrm{MPC}}\right)$ as well as the corresponding monthly average time series are displayed in Figs. 6, 7a and $\mathrm{b}$ respectively. In these figures and in accordance with the equations of Sect. 2.2., we recall that $F_{\text {CLOUD }}$ refers to time and $F_{\mathrm{MPC}}$ refers to time where clouds occur. One can note that MPCs are encountered in all seasons in the Arctic region. They seem to be linked to the surface type as larger occurrences are observed over ocean than over land, especially in the Greenland and Barents seas region. In particular from May to October, about $50 \%$ of the clouds over the entire Arctic region are MPCs (Fig. 7a). In winter and early spring, $F_{\text {MPC }}$ is close to $30 \%$. However, the spatial and temporal distribution of MPCs is highly inhomogeneous. Larger occurrences up to $60 \%$ are observed over the Greenland Sea throughout the year and over the Canadian Basin and the Chukchi Sea in autumn. Over the Svalbard region (Fig. $7 b$ ), $F_{\text {MPC }}$ is equal or larger compared to the Arctic average, and less contrasted, with values around $55 \%$, ranging between 45 and $60 \%$ all year long.

Figure 8a presents the vertical profiles of the mean seasonal vertical distribution $\left(F_{\mathrm{MPC}}(z)\right)$, over the whole Arctic 

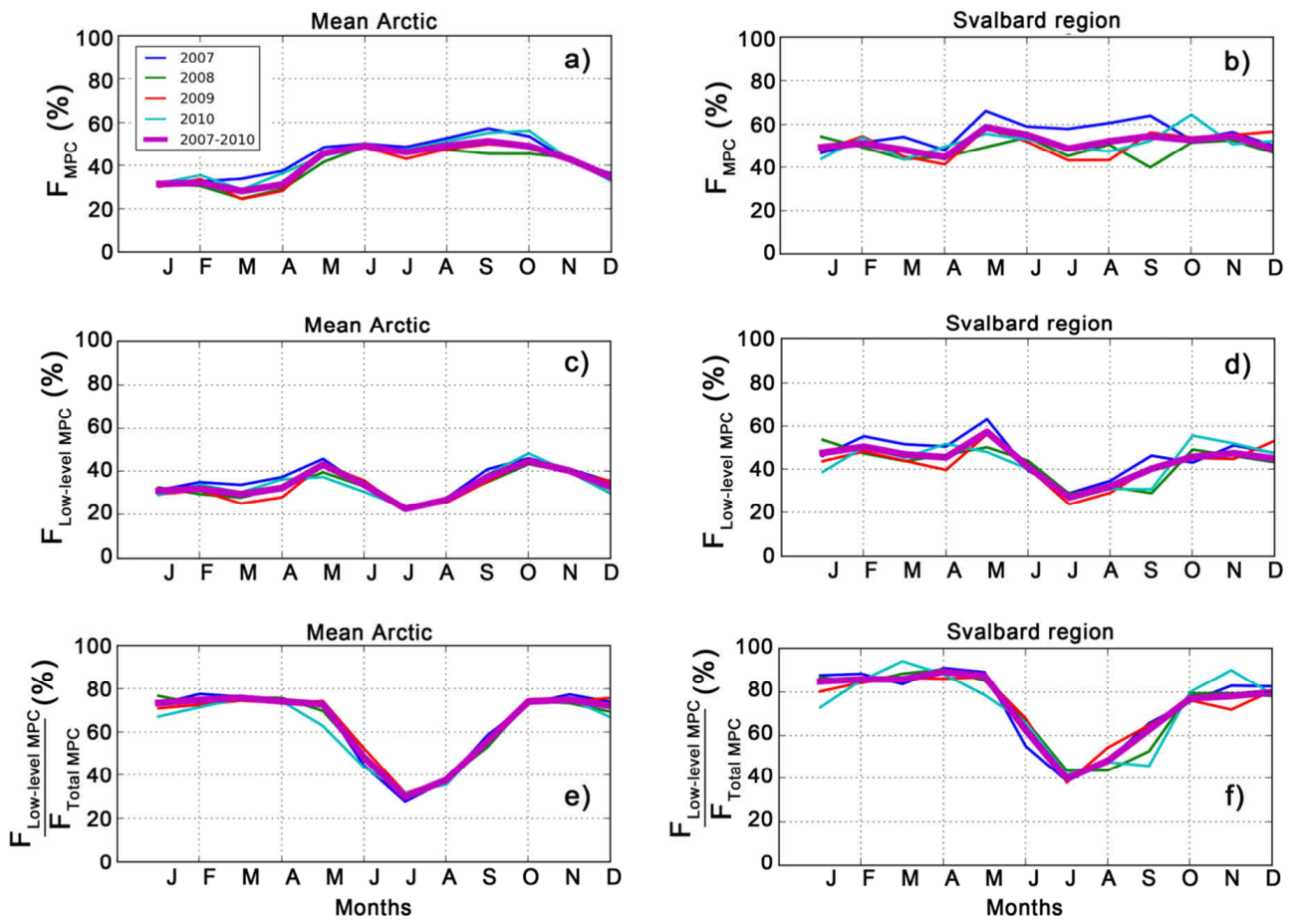

Figure 7. Monthly total MPC (a and b) and low-level MPC (c and d) occurrence, and ratio of low-level MPCs over total MPCs (e and f) over the whole Arctic region (left side panels) and over the Svalbard region (right side panels).

a)
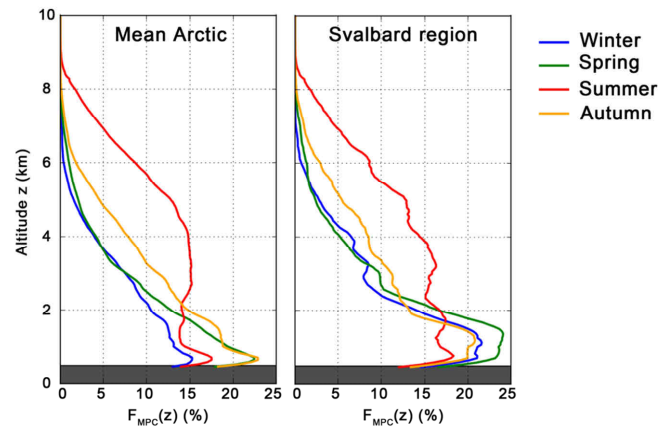

b)

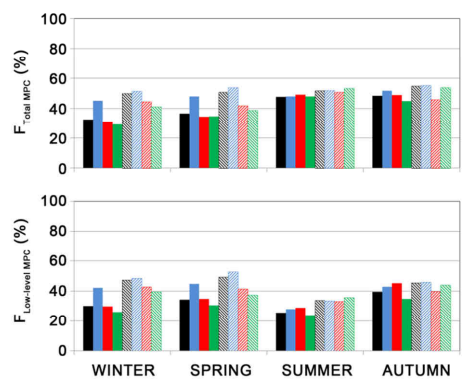

- Over the whole Arctic all surfaces - Over Arctic open water surface - Over Arctic sea ice surface n Over Acrtic land surface $\mathbb{Q}$ Over Svalbard all surfaces Over Svalbard open water surface Over Svalbard sea ice surface $\mathbb{Q}$ Over Svalbard land surface

Figure 8. (a) Mean seasonal vertical profiles of the MPC occurrence over the Arctic region (left panel) and over the Svalbard region (right panel); (b) mean seasonal MPC occurrence according to the surface type for all-level (500 m-12 km, top panel) and low-level ( $500 \mathrm{~m}-3 \mathrm{~km}$, bottom panel) altitudes.

and over the Svalbard region. The grey zone on each profile in Fig. 8a symbolises the region below $500 \mathrm{~m}$, where space remote sensing data are considered not accurate enough due to surface contamination. For altitudes below $3000 \mathrm{~m}$, and mainly over the Svalbard region, $F_{\mathrm{MPC}}(z)$ sharply increases with decreasing altitude except for summer observations. During the transition seasons (spring and autumn), the maximum occurrence of MPCs is reached between $500 \mathrm{~m}$ and $1500 \mathrm{~m}$ above sea level with values higher than $15 \%$ and $20 \%$ over the entire Arctic and over the Svalbard region respectively. Above a typical altitude of $3000 \mathrm{~m}$, the MPC frequencies decrease below $10 \%$. The main result from these figures is that MPCs prevail mainly at altitudes lower than $3000 \mathrm{~m}$ both over the whole Arctic and over the Svalbard region. The largest occurrences are observed below this altitude level with values almost twice as large as the ones encountered above. $F_{\mathrm{MPC}}(z)$ in both regions exhibit similar characteristics despite a more pronounced lowlevel cloud increase over the Svalbard region. However, in summer, the vertical profile $F_{\mathrm{MPC}}(z)$ is characterised by a higher cloud amount (above $3000 \mathrm{~m}$ ) and less clouds (below $3000 \mathrm{~m}$ ) than during the other seasons. This finding is confirmed by Figs. 7c-f, which display respectively the monthly low-level $F_{\text {MPC }}$ and the ratio of low-level MPC over total MPC. Monthly low-level $F_{\text {MPC }}$ is clearly characterised by two peaks in spring and autumn, and a clear decrease in summer over the Svalbard region as well as over the entire Arctic. Figures $7 \mathrm{e}, \mathrm{f}$ and $8 \mathrm{a}$ show that MPC clouds are mostly 


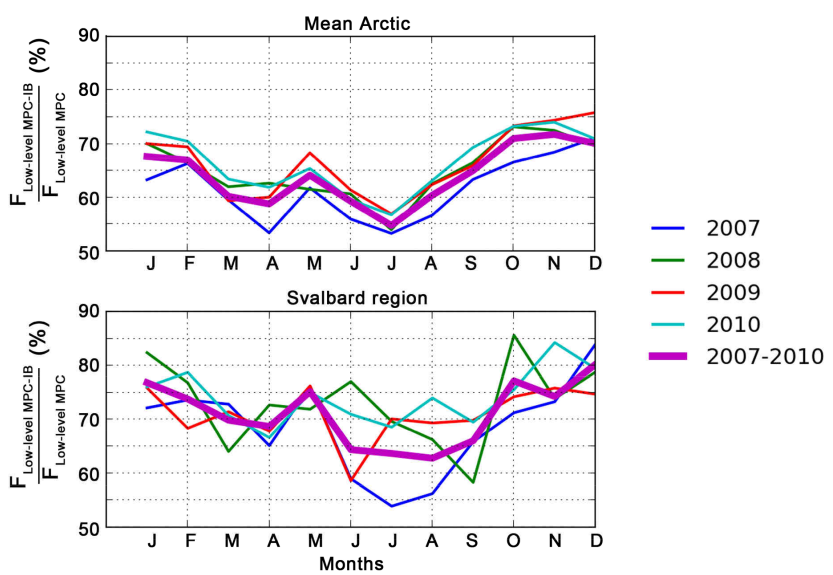

Figure 9. Monthly-averaged ratio of low-level MPC-IB over lowlevel MPC over the Arctic region (top) and over the Svalbard region (bottom).

confined to low altitudes, except in summer. As pictured in Figs. 7e and f, nearly 70 and $90 \%$ of the MPCs (over the Arctic region and the Svalbard region respectively) are located below $3000 \mathrm{~m}$. Summer season presents a large decrease of this ratio, with values down to $30 \%$ for the whole Arctic and $40 \%$ for the Svalbard region. In summer, low-level MPCs are less frequent (30\%), which is consistent with the vertical profiles displayed in Fig. 8a showing a significant occurrence of MPC in the mid-level altitude domain (3000-6000 m). Finally, Figs. 7e and $\mathrm{f}$ highlight that the fraction of low level MPCs in the Svalbard region is systematically higher than the Arctic average (10\% to $20 \%$ more, mainly in winter and spring).

Finally, Fig. 8b displays the mean seasonal $F_{\text {MPC }}$ computed from Eq. (1), (2) and (3), according to the surface type (open water, sea ice and land surfaces). This figure displays that MPCs are more prominent over open water than over sea ice and land. This difference is observed both over the entire Arctic as well as the Svalbard region, and both for low-level and all-level MPCs, except in summer. In particular during winter and spring, MPCs are more present over open water than land or sea ice by up to $15 \%$. This result is consistent with the spatial variability displayed in Fig. 6b. Moreover, results for all-level altitude domain $(500 \mathrm{~m}$ to $12 \mathrm{~km}$, Fig. $8 \mathrm{~b}$ top panel) and for low-level domain $(500 \mathrm{~m}$ to $3 \mathrm{~km}$, Fig. $8 \mathrm{~b}$ bottom panel) are quite similar. Only the summer period shows no significant differences according to surface type.

At last, we determine the occurrence of a specific type of Arctic MPCs: single-layer mixed-phase clouds characterised by a single supercooled liquid layer at the cloud top and ice below, precipitating down to the surface. This type of cloud will be noted thereafter MPC-IB (for mixed-phase cloud with ice below). In DARDAR products, pixels identified as mixed-phase and presenting at least three ice pixels a)

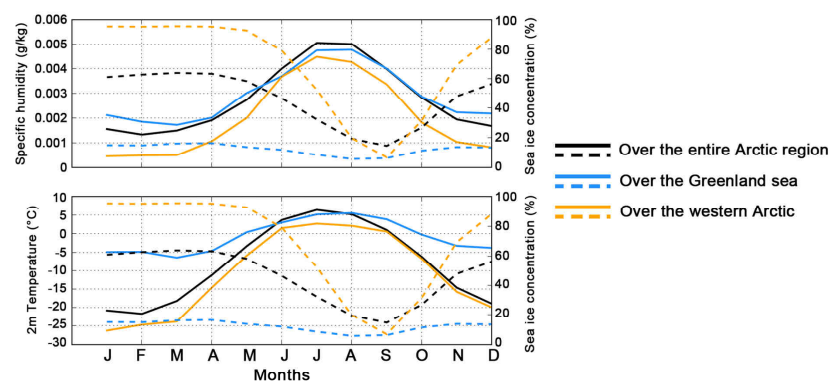

b)

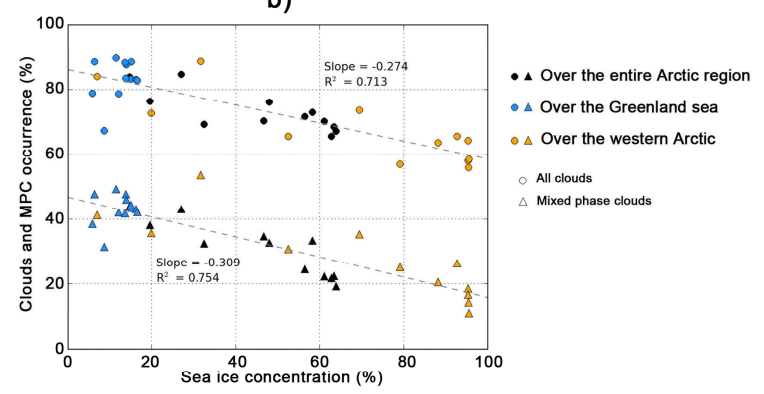

Figure 10. (a) Annual variability (monthly averaged) of specific humidity (straight lines on top panel) and $2 \mathrm{~m}$ temperature (straight lines on bottom panel) and sea ice concentration (dotted lines on each panel), and (b) Clouds (circle symbols) and MPC (triangle symbols) occurrences as a function of sea ice concentration. Colours refer to values over the whole Arctic region (black), over the Greenland sea (blue) and over the Western Arctic (orange).

below are classified as MPC-IB type. Clouds characterised by ice pixels above a liquid layer (i.e. corresponding to an embedded mixed-phase) are rejected.

First, we estimate the proportion of MPC-IB among MPCs. Figure 9 displays the ratio of MPC-IB over MPC for the low-altitude domain $(500 \mathrm{~m}-3 \mathrm{~km})$, both for the entire Arctic and the Svalbard region. The variability of this ratio is rather small throughout the year. The proportion of MPCIB among MPC varies between 55 and $70 \%$ over the whole Arctic and between 65 and $80 \%$ over the Svalbard region.

As was done for MPCs, the main characteristics of the MPC-IB occurrences are studied. The results are not shown here because the vertical distribution and seasonal variability of MPC-IB clouds are quite similar to those of MPCs: they are present all along the year, more frequently above open water than land or sea ice, and more frequently in the Svalbard region, particularly in spring.

However, MPC-IB statistics must be used with caution as the measurement uncertainties linked to the discrimination of multi-layer MPCs from single-layer MPCs based on CALIPSO/CLOUDSAT observations remains difficult to assess, as described in Sect. 2.3.2. For the purpose of comparison, only a few previous studies tried to quantify the multilayer cloud occurrence. For example, Verlinde et al. (2013) 
and Intrieri et al. (2002) describe that multi-layer clouds may be as frequent as single-layer clouds.

\section{Discussion}

In this study, the spatial and vertical occurrence of Arctic MPCs at the regional scale has been assessed. The results highlight that the Arctic, and particularly the Svalbard area, is a very favourable region for the formation and the evolution of MPCs and MPC-IB. However, all the processes controlling the MPC life cycle remain difficult to understand. Indeed, these processes are numerous and occur at different spatial and temporal scales, leading to complex interactions between them (Morrison et al., 2012). Additionally, the Arctic region benefits from peculiar meteorological conditions (Orbaek et al., 1999) and large-scale atmospheric circulation patterns.

The larger MPC and MPC-IB occurrences observed over the Svalbard compared to the Arctic average may be linked to the contribution of the humid air and warmer water transported from the North Atlantic Ocean. This specific synoptic regime brings to the Svalbard region (and region of Greenland sea) more moisture as compared to the rest of the Arctic (Serreze and Barry, 2005). Thus cloud formation and its development can be amplified, since the supply of moisture by the North Atlantic Ocean is favourable for the nucleation of liquid droplets. The initiation of new supercooled liquid droplets will balance the loss due to the WBF process within the MPCs, and therefore participate to maintain the equilibrium between ice and supercooled droplets. However, moisture is not sufficient by itself to maintain the ice-liquid equilibrium. As shown in Korolev et al. (2003), Korolev (2007) and Morrison et al. (2012), it has to be coupled with dynamics processes, such as updraft from cloud base, or turbulence and entrainment at cloud top. Moreover, winter and transition seasons are characterised most of the time by stable atmospheric conditions (Orbaek et al., 1999), coupled with a temperature range favourable for mixed-phase conditions. These conditions associated with temperature and eventually humidity inversions at the cloud top, which frequently occur in these seasons (Nygård et al., 2014; Sedlar et al., 2012), can contribute to the containment of Arctic clouds and MPCs at low altitudes by limiting their vertical extension. The summer and autumn seasons exhibit large occurrence values for MPCs in the Western Arctic (Chukchi and Canadian seas, Fig. 3a). During these seasons, the large open seas enable the warm water to be transported across the Arctic, resulting in warm and moist air advection in the Western Arctic. Open water facilitates the vertical transfer of moisture, responsible for an increase of cloud formation as compared to sea ice, which could explain the prevalence of MPCs during this period in the Western Arctic.

In an attempt to strengthen this assumption and to bring perspective to this work, a short analysis of the variability of sea ice extent is done and its potential link with humidity, temperature and cloud occurrence is investigated. Sea ice concentration data included in CALIOP Level 1 data from the National Snow and Ice Data Center (NSIDC) are used. Two specific areas are selected:

- over the Greenland Sea, between $70^{\circ}$ and $80^{\circ} \mathrm{N}$ and between $10^{\circ} \mathrm{W}$ and $20^{\circ} \mathrm{E}$;

- over the Western Arctic (Chukchi and Beaufort seas), between $70^{\circ}$ and $80^{\circ} \mathrm{N}$ and between 150 and $180^{\circ} \mathrm{W}$.

Figure 10a displays the annual variability of the specific humidity (top panel) and the $2 \mathrm{~m}$ temperature (bottom panel) in solid lines between 2007 and 2010 for the whole Arctic region (black), over the Greenland Sea (blue) and over the Western Arctic (orange). On both figures, dashed lines represent the sea ice concentration from NSIDC (in \%). Humidity and temperature are from ECMWF and are interpolated onto the DARDAR grid. Specific humidity is averaged over the $0-500 \mathrm{~m}$ altitude range. Note that the accuracy of these ECMWF retrievals is not discussed here since we use them only to demonstrate their variability.

From this figure, one can see that sea ice variability is very pronounced in the Western Arctic with a large decrease from late spring to late autumn (values larger than $90 \%$ in April decrease to less than $10 \%$ in September). Over the Greenland Sea, sea ice variability is rather small, with values between 5 and $20 \%$. A small decrease is still observed from spring to autumn. This figure highlights clearly that sea ice concentration is inversely correlated with humidity and temperature. Moreover, a delay is observed between the sea ice concentration minimum (September) and the temperature and humidity maxima (July).

Finally, Fig. 10b compares directly the total cloud and MPC occurrences with sea ice concentration. Cloud and MPC occurrences clearly decrease when sea ice concentration increases. This trend is observed both for all clouds and MPCs (slope around -0.30 , with a correlation coefficient of $0.7)$. Note that the results over the Greenland Sea (blue dots) do not point out a significant trend due to the small variability of the sea ice concentration throughout the year in this region. This is in agreement with the high cloud occurrence observed year-long in this region. From these results, it seems that cloud and MPC cover are linked to the sea ice melting. However, a more detailed investigation is needed to confirm this assumption, such as the study of cloud and sea ice over the entire Arctic region, since our study is limited to the region below $82^{\circ} \mathrm{N}$.

Therefore, the results of the present study seem to indicate that sea ice melting and large-scale circulation can have an important impact on MPC annual variability in the Arctic, by preventing warm water and moisture advection to the entire Arctic during winter and early spring, and favouring it the rest of the year (which is consistent with Kay and Gettelman (2009) and Palm et al., 2010). The decrease of low- 
level clouds and MPCs in summer could be explained by an increase in air temperature coupled with less stable atmospheric conditions than during the rest of the year, causing the formation of MPC at higher altitudes (as shown on vertical profiles in Fig. 8a).

At last, it is obvious that numerous other regional and local processes are involved in the MPC life cycle and exert an influence on their spatial and temporal variability. Further studies are needed to investigate these different processes and establish a link between them. For example, efforts are currently focused on the study of local sources or long-range transported aerosols in the Arctic region and their role to act as cloud condensation nuclei (CCN) or ice nuclei (IN). The link between the variations of aerosol concentrations or compositions and the MPC characteristics should be investigated as it might partially explain some of the variations in the cloud and MPC occurrences. It would improve our understanding in the aerosol-cloud interactions in the Arctic, like the studies performed by Avramov et al., 2011; Jackson et al., 2012 or Tjernström et al., 2014. Additionally, Orellana et al., 2011 and Tjernström et al., 2014 highlighted that sea ice melting during summer produces biogenic aerosol particles, which could potentially act as CCN or IN for cloud and MPC formation. The influence of the surface, the turbulence and dynamics effect at small and large temporal and spatial scales on MPC occurrence also needs to be assessed more accurately. The most difficult task remains to couple all these processes and quantify their respective importance in the Arctic MPC evolution.

\section{Conclusions and outlook}

This work presents a study of cloud and mixed-phase cloud occurrences over the Arctic region with a focus on the Svalbard region. The methodology used is based on satellite active remote sensing measurements. The CALIPSO/CLOUDSAT observations are processed with the DARDAR retrieval algorithm to perform a cloud thermodynamic phase classification. The uncertainties and limitations of this method are first evaluated from comparison with ground-based observations. The spatial frequencies of occurrence and vertical distributions are then determined for total cloud and MPCs, over the entire Arctic region and over the Svalbard region. The cloud occurrences are also investigated and discriminated according to the surface type (open water, sea ice and land). The main results are summarised below:

- Based on comparisons with ground-based observations, uncertainties in the determination of cloud and MPC occurrence from the DARDAR product below $2 \mathrm{~km}$ of altitude are estimated to up to $20 \%$ between $500 \mathrm{~m}$ and $2 \mathrm{~km}$, and around $25 \%$ below $500 \mathrm{~m}$.

- Clouds are present in the Arctic throughout the year, with occurrences between $50 \%$ and nearly $100 \%$, de- pending on the season and the location. Moreover, clouds are more frequent in the Svalbard region than in the rest of the Arctic by around 5-10\%.

- Over the whole Arctic region, MPCs represent around $30 \%$ of the clouds during winter and around $50 \%$ of the clouds the rest of the year. Over the Svalbard region, MPC occurrence is almost constant year-round, with values around $55 \%$. MPCs are mainly present at low-altitudes as 70 to $90 \%$ of the MPCs are located below $3 \mathrm{~km}$ (both for the entire Arctic and the Svalbard region), especially in winter, spring and autumn. In summer, the MPC occurrence becomes significant at mid-level altitudes $(3-6 \mathrm{~km})$. During spring, MPCs are located mainly over the Greenland, Barents and Norwegian seas. In autumn, large occurrences are observed in the Western Arctic (over the Chukchi and the Canadian seas). Moreover, MPCs are generally more frequently encountered over open sea than over land or sea ice.

- The particular Arctic MPCs composed of a single supercooled liquid layer at the cloud top and ice in the lower part of the cloud (MPC-IB) represent between 55 and $70 \%$ of the MPCs over the whole Arctic and between 65 and $80 \%$ of the MPC over the Svalbard region. Spatial, seasonal and vertical variability of this cloud type have strong similarities with MPCs.

- Differences between MPC seasonality over the Svalbard region and over the entire Arctic region can be partly explained by the vicinity of the North Atlantic Ocean and the particular atmospheric conditions encountered around the Svalbard archipelago. The mixture of cold air and warm water from the North Atlantic Ocean seems to be responsible for the large MPC amount observed during spring over the Svalbard. In the Western Arctic, the MPC maximum frequency occur later during summer and autumn when heat and moisture are released due to the melting of sea ice. A short analysis based on comparisons of sea ice concentration with temperature, humidity and clouds and MPC occurrences seems to establish a link between sea ice and cloud and MPC occurrences. Evidently, a more detailed study is needed here, as MPC variability is also dependent on the regional scale characteristics such as the oceanic circulation, and on more local conditions (such as the proportion of open water/sea ice which exhibits a seasonal variability).

Space remote sensing observations of Arctic MPCs at the regional scale highlighted large occurrence frequencies, in particular concerning low-level MPCs. Thus, the present study contributes to understand in which regional frame airborne campaigns and ground-based observations have been performed. However, space remote sensing observations present well-known uncertainties near the surface, 
which may have an important impact on low-level cloud amount determination. Therefore, airborne campaigns will provide a more thorough characterisation of MPC properties at a small scale. In particular, in situ measurements will help to understand the microphysical processes involved in MPCs.

As an example, in situ airborne measurements performed during the ASTAR 2007 and POLARCAT 2008 campaigns, in spring, over the open water around the Svalbard region and the Greenland sea, provided data from several boundary layer mixed-phase clouds with a typical MPC-IB structure (Gayet et al., 2009). Several ascents and descents in all of these clouds have been performed between the cloud top and the sea level. Despite the small amount of data collected and the fact that they are very localised in time and space, these in situ measurements can be considered a very useful data set for studying MPC at small scale.

In particular, the quantification of ice and liquid particle microphysical and optical properties, and the vertical profiles of water droplet and ice crystal microphysical properties, will give an insight into the microphysical processes responsible for particles growth within MPCs. Accurate profiles of relevant cloud parameters (for example asymmetry parameter, optical depth, ice/liquid water mass fraction, ice crystal morphology, size and concentration, among others) may also be provided to contribute to an improvement of cloud representation in global and meso-scale models and to improve airborne and spatial remote sensing retrieval algorithms, such as those of CALIPSO/CLOUDSAT, or in the near future, EarthCARE.

Finally, it would be of great interest to associate the present work with further studies at various scales, especially at a small scale. The synergy of in situ and remote sensing observations will allow the multi-scale study of MPCs and it will particularly help to resolve some actual unanswered questions concerning the definition of mixed-phase clouds according to the scale of observation. Such a multi-scale approach will, thus, improve the parameterisation of MPCs in remote sensing retrieval algorithms and their representation in models at different resolutions.

Acknowledgements. This work is part of the French scientific community EECLAT project (Expecting EarthCare, Learning from A-Train) and is supported by the French Centre National des Etudes Spatiales (CNES). This research used resources from the ICARE centre for space remote sensing data processing. This work was also supported by the French ANR CLIMSLIP project (Climate Impacts of Short-Lived Pollutants and Methane in the Arctic). We thank the anonymous reviewers who made important comments that helped to strengthen the manuscript.

Edited by: M. Krämer

\section{References}

Avramov, A., Ackerman, A. S., Fridlind, A. M., van Diedenhoven, B., Botta, G., Aydin, K., Verlinde, J., Korolev, A. V., Strapp, J. W., McFarquhar, G. M., Jackson, R., Brooks, S. D., Glen, A., and Wolde, M.: Toward ice formation closure in Arctic mixedphase boundary layer clouds during ISDAC, J. Geophys. Res., 116, D00T08, doi:10.1029/2011JD015910, 2011.

Baumgardner, D., Avallone, L., Bansemer, A., Borrmann, S., Brown, P., Bundke, U., Chuang, P. Y., Cziczo, D., Field, P., Gallagher, M., Gayet, J.-F., Heymsfield, A., Korolev, A., Krämer, M., McFarquhar, G., Mertes, S., Möhler, O., Lance, S., Lawson, P., Petters, M. D., Pratt, K., Roberts, G., Rogers, D., Stetzer, O., Stith, J., Strapp, W., Twohy, C., and Wendisch, M.: In Situ, Airborne Instrumentation: Addressing and Solving Measurement Problems in Ice Clouds, Bull. Am. Meteorol. Soc., 93, ES29ES34, doi:10.1175/BAMS-D-11-00123.1, 2012.

Benedetti, A.: CloudSat AN-ECMWF ancillary data interface control document, technical document, CloudSat Data Process. Cent., 16th July, 2005.

Bergeron, T.: On the physics of clouds and precipitation, Int. Union Geod. Geophys., 156-178, 1935.

Bierwirth, E., Ehrlich, A., Wendisch, M., Gayet, J.-F., Gourbeyre, C., Dupuy, R., Herber, A., Neuber, R., and Lampert, A.: Optical thickness and effective radius of Arctic boundary-layer clouds retrieved from airborne nadir and imaging spectrometry, Atmospheric Meas. Tech., 6, 1189-1200, doi:10.5194/amt-6-11892013, 2013.

Blanchard, Y., Pelon, J., Eloranta, E. W., Moran, K. P., Delanoë, J., and Sèze, G.: A synergistic analysis of cloud cover and vertical distribution from A-Train and ground-based sensors over the high Arctic station EUREKA from 2006 to 2010, J. Appl. Meteorol. Clim., 53, 11, 2553-2570, 2014

De Boer, G., Chapman, W., Kay, J. E., Medeiros, B., Shupe, M. D., Vavrus, S. and Walsh, J.: A Characterization of the PresentDay Arctic Atmosphere in CCSM4, J. Climate, 25, 2676-2695, doi:10.1175/JCLI-D-11-00228.1, 2012.

De Boer, G., Eloranta, E. W., and Shupe, M. D.: Arctic Mixed-Phase Stratiform Cloud Properties from Multiple Years of SurfaceBased Measurements at Two High-Latitude Locations, J. Atmos. Sci., 66, 2874-2887, doi:10.1175/2009JAS3029.1, 2009.

Bourdages, L., Duck, T. J., Lesins, G., Drummond, J. R., and Eloranta, E. W.: Physical properties of High Arctic tropospheric particles during winter, Atmos. Chem. Phys., 9, 6881-6897, doi:10.5194/acp-9-6881-2009, 2009.

Ceccaldi, M., Delanoë, J., Hogan, R. J., Pounder, N. L., Protat, A., and Pelon, J.: From CloudSat-CALIPSO to EarthCare: Evolution of the DARDAR cloud classification and its comparison to airborne radar-lidar observations, J. Geophys. Res. Atmos., 118, 1-20, doi:10.1002/jgrd.50579, 2013.

Cesana, G., Kay, J. E., Chepfer, H., English, J. M. and de Boer, G.: Ubiquitous low-level liquid-containing Arctic clouds: New observations and climate model constraints from CALIPSO-GOCCP, Geophys. Res. Lett., 39, L20804, 1-6, doi:10.1029/2012GL053385, 2012.

Chan, M. A. and Comiso, J. C.: Arctic Cloud Characteristics as Derived from MODIS, CALIPSO, and CloudSat, J. Climate, 26, 3285-3306, doi:10.1175/JCLI-D-12-00204.1, 2013.

Chernokulsky, A. and Mokhov, I. I.: Climatology of Total Cloudiness in the Arctic: An Intercomparison of Ob- 
servations and Reanalyses, Adv. Meteorol., 2012, 1-15, doi:10.1155/2012/542093, 2012.

Choi, Y.-S., Ho, C.-H., Park, C.-E., Storelvmo, T., and Tan, I.: Influence of cloud phase composition on climate feedbacks, J. Geophys. Res. Atmos., 119, 3687-3700, doi:10.1002/2013JD020582, 2014.

Curry, J. A.: Interactions among aerosols, clouds, and climate of the Arctic Ocean, Sci. Tot. Environ., 160-161, 777-791, doi:10.1016/0048-9697(95)04411-S, 1995.

Curry, J. A., Hobbs, P. V., King, M. D., Randall, D. A., Minnis, P., Isaac, G. A., Pinto, J. O., Uttal, T., Bucholtz, A., Cripe, D. G., Gerber, H., Fairall, C. W., Garrett, T. J., Hudson, J., Intrieri, J. M., Jakob, C., Jensen, T., Lawson, P., Marcotte, D., Nguyen, L., Pilewskie, P., Rangno, A., Rogers, D. C., Strawbridge, K. B., Valero, F. P. J., Williams, A. G., and Wylie, D.: FIRE Arctic Clouds Experiment, Bull. Am. Meteorol. Soc., 81, 5-29, doi:10.1175/15200477(2000)081<0005:FACE>2.3.CO;2, 2000.

Curry, J. A., Pinto, J. O., Benner, T., and Tschudi, M.: Evolution of the cloudy boundary layer during the autumnal freezing of the Beaufort Sea, J. Geophys. Res., 102, 13851, doi:10.1029/96JD03089, 1997.

Curry, J. A., Schramm, J. L., Rossow, W. B., and Randall, D.: Overview of Arctic Cloud and Radiation Characteristics, J. Climate, 9, 1731-1764, doi:10.1175/15200442(1996)009<1731:OOACAR>2.0.CO;2, 1996.

Delanoë, J. and Hogan, R. J.: A variational scheme for retrieving ice cloud properties from combined radar, lidar, and infrared radiometer, J. Geophys. Res., 113, doi:10.1029/2007JD009000, 2008.

Delanoë, J. and Hogan, R. J.: Combined CloudSat-CALIPSOMODIS retrievals of the properties of ice clouds, J. Geophys. Res., 115, doi:10.1029/2009JD012346, 2010.

Delanoë, J., Protat, A., Jourdan, O., Pelon, J., Papazzoni, M., Dupuy, R., Gayet, J.-F., and Jouan, C.: Comparison of Airborne In Situ, Airborne Radar-Lidar, and Spaceborne RadarLidar Retrievals of Polar Ice Cloud Properties Sampled during the POLARCAT Campaign, J. Atmos. Ocean. Techn., 30, 57-73, doi:10.1175/JTECH-D-11-00200.1, 2013.

Dong, X., Xi, B., Crosby, K., Long, C. N., Stone, R. S., and Shupe, M. D.: A 10 year climatology of Arctic cloud fraction and radiative forcing at Barrow, Alaska, J. Geophys. Res., 115, D17212, doi:10.1029/2009JD013489, 2010.

Findeisen, W.: Kolloid-meteorologische vorgange bei neiderschlags-bildung, Meteorol Z, 55, 121-133, 1938.

Frey, R. A., Ackerman, S. A., Liu, Y., Strabala, K. I., Zhang, H., Key, J. R., and Wang, X.: Cloud Detection with MODIS. Part I: Improvements in the MODIS Cloud Mask for Collection 5, J. Atmos. Ocean. Tech., 25, 1057-1072, doi:10.1175/2008JTECHA1052.1, 2008.

Garrett, T. J., Maestas, M. M., Krueger, S. K., and Schmidt, C. T.: Acceleration by aerosol of a radiative-thermodynamic cloud feedback influencing Arctic surface warming, Geophys. Res. Lett., 36, L19804, doi:10.1029/2009GL040195, 2009.

Gayet, J.-F., Mioche, G., Dörnbrack, A., Ehrlich, A., Lampert, A., and Wendisch, M.: Microphysical and optical properties of Arctic mixed-phase clouds. The 9 April 2007 case study., Atmos. Chem. Phys., 9, 6581-6595, doi:10.5194/acp-9-6581-2009, 2009.
Gultepe, I., Isaac, G., Hudak, D., Nissen, R. and Strapp, J. W.: Dynamical and Microphysical Characteristics of Arctic Clouds during BASE, J. Climate, 13, 1225-1254, doi:10.1175/15200442(2000)013<1225:DAMCOA>2.0.CO;2, 2000.

Harrington, J. Y., Reisin, T., Cotton, W. R., and Kreidenweis, S. M.: Cloud resolving simulations of Arctic stratus, Atmos. Res., 51, 45-75, doi:10.1016/S0169-8095(98)00098-2, 1999.

Hobbs, P. V. and Rangno, A. L.: Microstructures of low and middlelevel clouds over the Beaufort Sea, Q. J. R. Meteorol. Soc., 124, 2035-2071, doi:10.1002/qj.49712455012, 1998.

Hoffmann, A., Ritter, C., Stock, M., Shiobara, M., Lampert, A., Maturilli, M., Orgis, T., Neuber, R., and Herber, A.: Ground-based lidar measurements from Ny-Ålesund during ASTAR 2007, Atmospheric Chem. Phys., 9, 9059-9081, doi:10.5194/acp-9-90592009, 2009.

Huang, Y., Siems, S. T., Manton, M. J., Protat, A., and Delanoë, J.: A study on the low-altitude clouds over the Southern Ocean using the DARDAR-MASK, J. Geophys. Res. Atmos., 117, D18204, 1-15, doi:10.1029/2012JD017800, 2012.

Intrieri, J. M., Shupe, M. D., Uttal, T., and McCarty, B. J.: An annual cycle of Arctic cloud characteristics observed by radar and lidar at SHEBA, J. Geophys. Res., 107, doi:10.1029/2000JC000423, 2002.

Jackson, R. C., McFarquhar, G. M., Korolev, A. V., Earle, M. E., Liu, P. S. K., Lawson, R. P., Brooks, S., Wolde, M., Laskin, A., and Freer, M.: The dependence of ice microphysics on aerosol concentration in arctic mixed-phase stratus clouds during ISDAC and M-PACE, J. Geophys. Res., 117, D15207, doi:10.1029/2012JD017668, 2012.

Jouan, C., Girard, E., Pelon, J., Gultepe, I., Delanoë, J., and Blanchet, J.-P.: Characterization of Arctic ice cloud properties observed during ISDAC, J. Geophys. Res., 117, D23207, doi:10.1029/2012JD017889, 2012.

Jouan, C., Pelon, J., Girard, E., Ancellet, G., Blanchet, J. P., and Delanoë, J.: On the relationship between Arctic ice clouds and polluted air masses over the North Slope of Alaska in April 2008, Atmos. Chem. Phys., 14, 1205-1224, doi:10.5194/acp-14-12052014, 2014.

Jourdan, O., Mioche, G., Garrett, T. J., Schwarzenböck, A., Vidot, J., Xie, Y., Shcherbakov, V., Yang, P., and Gayet, J.-F.: Coupling of the microphysical and optical properties of an Arctic nimbostratus cloud during the ASTAR 2004 experiment: Implications for light-scattering modeling, J. Geophys. Res., 115(D23206), doi:10.1029/2010JD014016, 2010.

Kay, J. E. and Gettelman, A.: Cloud influence on and response to seasonal Arctic sea ice loss, J. Geophys. Res., 114, D18204, doi:10.1029/2009JD011773, 2009.

Key, J. and Barry, R. G.: Cloud cover analysis with Arctic AVHRR data: 1. Cloud detection, J. Geophys. Res., 94, D15, 18521, doi:10.1029/JD094iD15p18521, 1989.

Klein, S. A., McCoy, R. B., Morrison, H., Ackerman, A. S., Avramov, A., Boer, G. de, Chen, M., Cole, J. N. S., Del Genio, A. D., Falk, M., Foster, M. J., Fridlind, A., Golaz, J.-C., Hashino, T., Harrington, J. Y., Hoose, C., Khairoutdinov, M. F., Larson, V. E., Liu, X., Luo, Y., McFarquhar, G. M., Menon, S., Neggers, R. A. J., Park, S., Poellot, M. R., Schmidt, J. M., Sednev, I., Shipway, B. J., Shupe, M. D., Spangenberg, D. A., Sud, Y. C., Turner, D. D., Veron, D. E., Salzen, K., von, Walker, G. K., Wang, Z., Wolf, A. B., Xie, S., Xu, K.-M., Yang, F., and Zhang, G.: In- 
tercomparison of model simulations of mixed-phase clouds observed during the ARM Mixed-Phase Arctic Cloud Experiment. I: single-layer cloud, Q. J. R. Meteorol. Soc., 135, 979-1002, doi:10.1002/qj.416, 2009.

Klingebiel, M., de Lozar, A., Molleker, S., Weigel, R., Roth, A., Schmidt, L., Meyer, J., Ehrlich, A., Neuber, R., Wendisch, M., and Borrmann, S.: Arctic low-level boundary layer clouds: in situ measurements and simulations of mono- and bimodal supercooled droplet size distributions at the top layer of liquid phase clouds, Atmos. Chem. Phys., 15, 617-631, doi:10.5194/acp-15617-2015, 2015.

Komurcu, M., Storelvmo, T., Tan, I., Lohmann, U., Yun, Y., Penner, J. E., Wang, Y., Liu, X., and Takemura, T.: INter-comparison of the cloud water phase among global climate models: cloud water phase in GCMs, J. Geophys. Res. Atmos., 119, 3372-3400, doi:10.1002/2013JD021119, 2014.

Korolev, A.: Limitations of the Wegener-Bergeron-Findeisen Mechanism in the Evolution of Mixed-Phase Clouds, J. Atmos. Sci., 64, 3372-3375, doi:10.1175/JAS4035.1, 2007.

Korolev, A. and Isaac, G.: Phase transformation of mixedphase clouds, Q. J. R. Meteorol. Soc., 129, 19-38, doi:10.1256/qj.01.203, 2003.

Korolev, A. V., Isaac, G. A., Cober, S. G., Strapp, J. W., and Hallett, J.: Microphysical characterization of mixed-phase clouds, Q. J. R. Meteorol. Soc., 129, 39-65, doi:10.1256/qj.01.204, 2003.

Liu, Y., Ackerman, S. A., Maddux, B. C., Key, J. R., and Frey, R. A.: Errors in Cloud Detection over the Arctic Using a Satellite Imager and Implications for Observing Feedback Mechanisms, J. Climate, 23, 1894-1907, doi:10.1175/2009JCLI3386.1, 2010.

Liu, Y., Key, J. R., Ackerman, S. A., Mace, G. G., and Zhang, Q.: Arctic cloud macrophysical characteristics from CloudSat and CALIPSO, Remote Sens. Environ., 124, 159-173, doi:10.1016/j.rse.2012.05.006, 2012.

Lubin, D. and Vogelmann, A. M.: A climatologically significant aerosol longwave indirect effect in the Arctic, Nature, 439, 453456, doi:10.1038/nature04449, 2006.

Luo, Y., Xu, K.-M., Morrison, H., McFarquhar, G. M., Wang, Z., and Zhang, G.: Multi-layer arctic mixed-phase clouds simulated by a cloud-resolving model: Comparison with ARM observations and sensitivity experiments, J. Geophys. Res., 113, D12208, doi:10.1029/2007JD009563, 2008.

Mace, G.: Level 2 GEOPROF product process description and interface control document algorithm version 5.3, 44, 2007.

Marchand, R., Mace, G. G., Ackerman, T. and Stephens, G.: Hydrometeor Detection Using Cloudsat - An Earth-Orbiting 94-GHz Cloud Radar, J. Atmos. Ocean. Tech., 25, 519-533, doi:10.1175/2007JTECHA1006.1, 2008.

McFarquhar, G. M., Ghan, S., Verlinde, J., Korolev, A., Strapp, J. W., Schmid, B., Tomlinson, J. M., Wolde, M., Brooks, S. D., Cziczo, D., Dubey, M. K., Fan, J., Flynn, C., Gultepe, I., Hubbe, J., Gilles, M. K., Laskin, A., Lawson, P., Leaitch, W. R., Liu, P., Liu, X., Lubin, D., Mazzoleni, C., Macdonald, A.-M., Moffet, R. C., Morrison, H., Ovchinnikov, M., Shupe, M. D., Turner, D. D., Xie, S., Zelenyuk, A., Bae, K., Freer, M., and Glen, A.: Indirect and Semi-direct Aerosol Campaign: The Impact of Arctic Aerosols on Clouds, Bull. Am. Meteorol. Soc., 92, 183-201, doi:10.1175/2010BAMS2935.1, 2011.
Morrison, H., de Boer, G., Feingold, G., Harrington, J., Shupe, M. D., and Sulia, K.: Resilience of persistent Arctic mixed-phase clouds, Nat. Geosci., 5, 11-17, doi:10.1038/ngeo1332, 2012.

Morrison, H., McCoy, R. B., Klein, S. A., Xie, S., Luo, Y., Avramov, A., Chen, M., Cole, J. N. S., Falk, M., Foster, M. J., Del Genio, A. D., Harrington, J. Y., Hoose, C., Khairoutdinov, M. F., Larson, V. E., Liu, X., McFarquhar, G. M., Poellot, M. R., von Salzen, K., Shipway, B. J., Shupe, M. D., Sud, Y. C., Turner, D. D., Veron, D. E., Walker, G. K., Wang, Z., Wolf, A. B., Xu, K.-M., Yang, F., and Zhang, G.: Intercomparison of model simulations of mixed-phase clouds observed during the ARM MixedPhase Arctic Cloud Experiment. II: Multilayer cloud, Q. J. R. Meteorol. Soc., 135, 1003-1019, doi:10.1002/qj.415, 2009.

Nygård, T., Valkonen, T., and Vihma, T.: Characteristics of Arctic low-tropospheric humidity inversions based on radio soundings, Atmos. Chem. Phys., 14, 1959-1971, doi:10.5194/acp-14-19592014, 2014.

Orbaek, J. B., Hisdal, V., and Svaasand, L. E.: Radiation climate variability in Svalbard: surface and satellite observations, Polar Res., 18, 127-134, 1999.

Orellana, M. V., Matrai, P. A., Leck, C., Rauschenberg, C. D., Lee, A. M., and Coz, E.: Marine microgels as a source of cloud condensation nuclei in the high Arctic, Proc. Natl. Acad. Sci., 108, 13612-13617, doi:10.1073/pnas.1102457108, 2011.

Palm, S. P., Strey, S. T., Spinhirne, J., and Markus, T.: Influence of Arctic sea ice extent on polar cloud fraction and vertical structure and implications for regional climate, J. Geophys. Res., 115, D21209, doi:10.1029/2010JD013900, 2010.

Rossow, W. B. and Garder, L. C.: Cloud Detection Using Satellite Measurements of Infrared and Visible Radiances for ISCCP, J. Climate, 6, 2341-2369, doi:10.1175/15200442(1993)006<2341:CDUSMO>2.0.CO;2, 1993.

Sanderson, M. G., Hemming, D. L., and Betts, R. A.: Regional temperature and precipitation changes under high-end $\left(=4{ }^{\circ} \mathrm{C}\right)$ global warming, Philos. T. Roy. Soc. A, 369, 85-98, doi:10.1098/rsta.2010.0283, 2011.

Schweiger, A. J. and Key, J. R.: Arctic cloudiness: comparison of ISCCP-C2 and Nimbus-7 satellite-derived cloud products with a surface-based cloud climatology, J. Climate, 5, 1514-1527, doi:10.1175/1520-0442(1992)005<1514:ACCOIC>2.0.CO;2, 1992.

Sedlar, J., Shupe, M. D., and Tjernström, M.: On the relationship between thermodynamic structure and cloud top, and its climate significance in the Arctic, J. Climate, 25, 2374-2393, doi:10.1175/JCLI-D-11-00186.1, 2012.

Serreze, M. C. and Barry, R. G.: The Arctic Climate System, Cambridge University Press, Cambridge, UK, 2005.

Serreze, M. C., Barrett, A. P., Stroeve, J. C., Kindig, D. N., and Holland, M. M.: The emergence of surface-based Arctic amplification, The Cryosphere, 3, 11-19, doi:10.5194/tc-3-11-2009, 2009.

Shupe, M. D.: Clouds at Arctic Atmospheric Observatories, Part II: thermodynamic phase characteristics, J. Appl. Meteorol. Clim., 50, 645-661, doi:10.1175/2010JAMC2468.1, 2011.

Shupe, M. D. and Intrieri, J. M.: Cloud Radiative Forcing of the Arctic Surface: The Influence of Cloud Properties, Surface Albedo, and Solar Zenith Angle, J. Climate, 17, 616-628, doi:10.1175/1520-0442(2004)017<0616:crfota>2.0.co;2, 2004.

Shupe, M. D., Uttal, T., and Matrosov, S. Y.: Arctic cloud microphysics retrievals from surface-based remote sen- 
sors at SHEBA, J. Appl. Meteorol., 44, 1544-1562, doi:10.1175/JAM2297.1, 2005.

Shupe, M. D., Matrosov, S. Y., and Uttal, T.: Arctic mixedphase cloud properties derived from surface-based sensors at SHEBA, J. Atmos. Sci., 63, 697-711, doi:10.1175/JAS3659.1, 2006.

Shupe, M. D., Walden, V. P., Eloranta, E., Uttal, T., Campbell, J. R., Starkweather, S. M., and Shiobara, M.: Clouds at Arctic Atmospheric Observatories, Part I: occurrence and macrophysical properties, J. Appl. Meteorol. Clim., 50, 626-644, doi:10.1175/2010JAMC2467.1, 2011

Solomon, S., Qin, D., Manning, M., Chen, Z., Marquis, M., Averyt, K. B., Tignor, M., and Miller, H. L.: Climate change 2007: the physical scence basis, Cambridge University Press, Cambridge, UK., 2007.

Stephens, G. L.: Cloud feedbacks in the climate system: a critical review, J. Climate, 18, 237-273, 2005.

Stephens, G. L., Vane, D. G., Boain, R. J., Mace, G. G., Sassen, K., Wang, Z., Illingworth, A. J., O'Connor, E. J., Rossow, W. B., Durden, S. L., Miller, S. D., Austin, R. T., Benedetti, A., Mitrescu, C., and CloudSat Science Team: The CloudSat mission and the A-Train: a new dimension of space-based observations of clouds and precipitation, B. Am. Meteorol. Soc., 83, 1771-1790, doi:10.1175/BAMS-83-12-1771, 2002.

Thomas, S. M., Heidinger, A. K., and Pavolonis, M. J.: Comparison of NOAA's operational AVHRR-derived cloud amount to other satellite-derived cloud climatologies, J. Climate, 17, 4805-4822, 2004.

Tjernström, M., Leck, C., Birch, C. E., Bottenheim, J. W., Brooks, B. J., Brooks, I. M., Bäcklin, L., Chang, R. Y.-W., de Leeuw, G., Di Liberto, L., de la Rosa, S., Granath, E., Graus, M., Hansel, A., Heintzenberg, J., Held, A., Hind, A., Johnston, P., Knulst, J., Martin, M., Matrai, P. A., Mauritsen, T., Müller, M., Norris, S. J., Orellana, M. V., Orsini, D. A., Paatero, J., Persson, P. O. G., Gao, Q., Rauschenberg, C., Ristovski, Z., Sedlar, J., Shupe, M. D., Sierau, B., Sirevaag, A., Sjogren, S., Stetzer, O., Swietlicki, E., Szczodrak, M., Vaattovaara, P., Wahlberg, N., Westberg, M., and Wheeler, C. R.: The Arctic Summer Cloud Ocean Study (ASCOS): overview and experimental design, Atmos. Chem. Phys., 14, 2823-2869, doi:10.5194/acp-14-2823-2014, 2014.
Uttal, T., Curry, J. A., Mcphee, M. G., Perovich, D. K., Moritz, R. E., Maslanik, J. A., Guest, P. S., Stern, H. L., Moore, J. A., Turenne, R., Heiberg, A., Serreze, M. C., Wylie, D. P., Persson, O. G., Paulson, C. A., Halle, C., Morison, J. H., Wheeler, P. A., Makshtas, A., Welch, H., Shupe, M. D., Intrieri, J. M., Stamnes, K., Lindsey, R. W., Pinkel, R., Pegau, W. S., Stanton, T. P., and Grenfeld, T. C.: Surface heat budget of the Arctic Ocean, B. Am. Meteorol. Soc., 83, 255-275, doi:10.1175/1520-0477(2002)083<0255:SHBOTA>2.3.CO;2, 2002.

Verlinde, J., Harrington, J. Y., Yannuzzi, V. T., Avramov, A., Greenberg, S., Richardson, S. J., Bahrmann, C. P., McFarquhar, G. M., Zhang, G., Johnson, N., Poellot, M. R., Mather, J. H., Turner, D. D., Eloranta, E. W., Tobin, D. C., Holz, R., Zak, B. D., Ivey, M. D., Prenni, A. J., DeMott, P. J., Daniel, J. S., Kok, G. L., Sassen, K., Spangenberg, D., Minnis, P., Tooman, T. P., Shupe, M., Heymsfield, A. J., and Schofield, R.: The Mixed-Phase Arctic Cloud Experiment, B. Am. Meteorol. Soc., 88, 205-221, doi:10.1175/BAMS-88-2-205, 2007.

Verlinde, J., Rambukkange, M. P., Clothiaux, E. E., McFarquhar, G. M., and Eloranta, E. W.: Arctic multilayered, mixedphase cloud processes revealed in millimeter-wave cloud radar Doppler spectra, J. Geophys. Res.-Atmos., 118, 13199-13213, doi:10.1002/2013JD020183, 2013.

Wang, X. and Key, J. R.: Arctic surface, cloud, and radiation properties based on the AVHRR Polar Pathfinder Dataset, Part I: spatial and temporal characteristics, J. Climate, 18, 2558-2574, doi:10.1175/JCLI3438.1, 2005.

Wegener, A.: Thermodynamik der Atmosphare, J. A. Barth, Leipzig, 1911.

Wielicki, B. A., Barkstrom, B. R., Harrison, E. F., Lee, R. B. Louis Smith, G., and Cooper, J. E.: Clouds and the Earth's Radiant Energy System (CERES): an earth observing system experiment, B. Am. Meteorol. Soc., 77, 853-868, doi:10.1175/15200477(1996)077<0853:CATERE>2.0.CO;2, 1996.

Winker, D. M., Pelon, J. R., and McCormick, M. P.: The CALIPSO Mission: Spaceborne Lidar for Observation of Aerosols and Clouds, Proceedings of SPIE, 4893, Hangzhou, China, 1-11, 2003.

Zygmuntowska, M., Mauritsen, T., Quaas, J., and Kaleschke, L.: Arctic Clouds and Surface Radiation - a critical comparison of satellite retrievals and the ERA-Interim reanalysis, Atmos. Chem. Phys., 12, 6667-6677, doi:10.5194/acp-12-6667-2012, 2012. 